Document downloaded from:

http://hdl.handle.net/10251/67555

This paper must be cited as:

Payri González, F.; Payri, R.; Salvador Rubio, FJ.; Martínez López, J. (2012). A contribution to the understanding of cavitation effects in Diesel injector nozzles through a combined experimental and computational investigation. Computers and Fluids. 58:88-101. doi:10.1016/j.compfluid.2012.01.005.

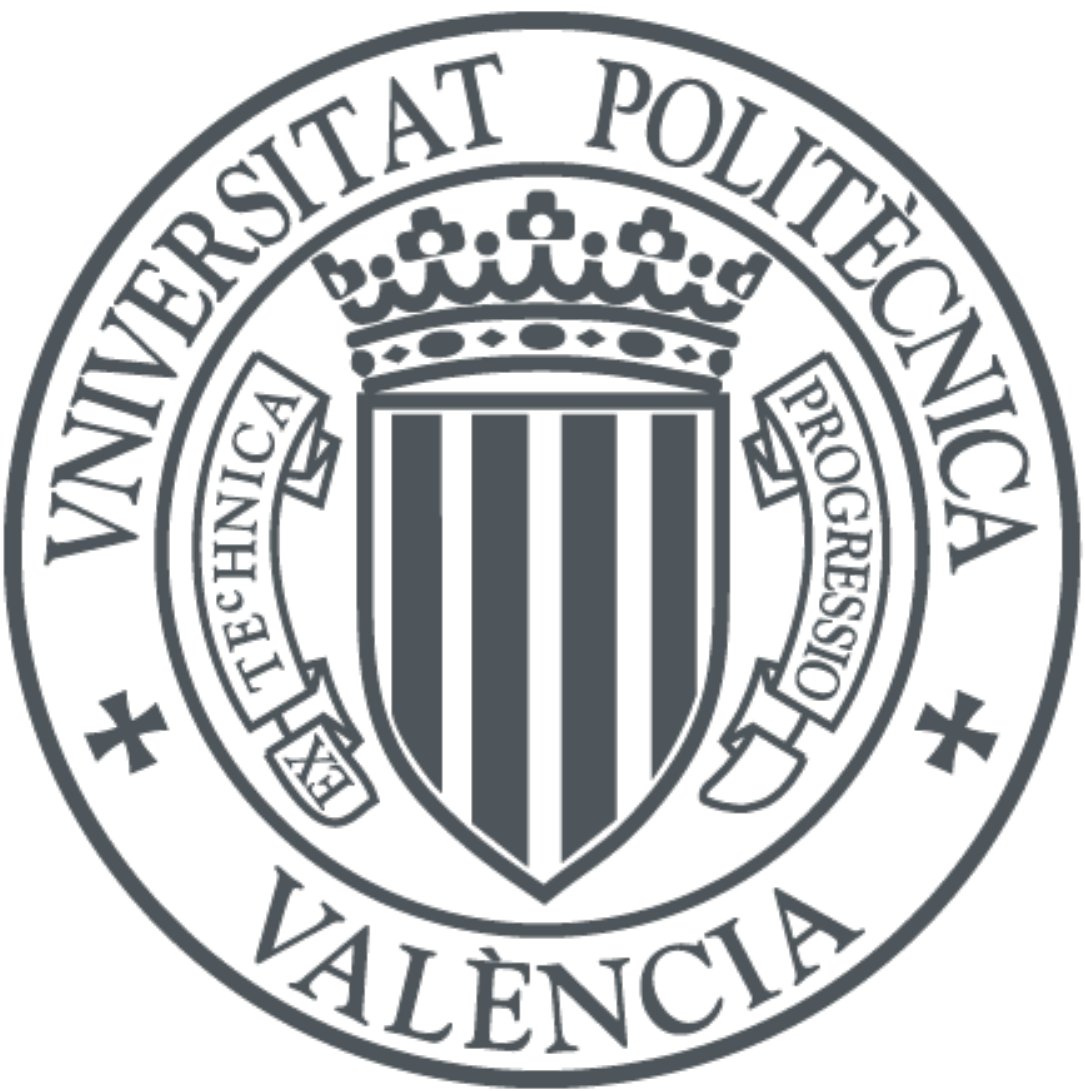

The final publication is available at

http://dx.doi.org/10.1016/j.compfluid.2012.01.005

Copyright Elsevier

Additional Information 
Computers \& Fluids 58 (2012) 88-101

\section{A CONTRIBUTION TO THE UNDERSTANDING OF CAVITATION EFFECTS IN DIESEL INJECTOR NOZZLES THROUGH A COMBINED EXPERIMENTAL AND COMPUTATIONAL INVESTIGATION.}

Payri, F., Payri, R., Salvador, F.J.(*), Martínez-López, J.

CMT-Motores Térmicos, Universidad Politécnica de Valencia

Camino de Vera s/n, E-46022 Spain.

(*) Corresponding author:

Dr. F. Javier Salvador, fsalvado@mot.upv.es

CMT-Motores Térmicos, Universidad Politécnica de Valencia

Camino de Vera s/n, E-46022 Spain.

Telephone: +34-963879659

FAX: $+34-963877659$

\section{ABSTRACT}

In this paper a combined experimental and computational study was carried out in order to assess the ability of a Homogeneous Equilibrium Model in predicting the experimental behaviour observed from the hydraulical characterization of a nozzle. The nozzle used was a six-orifice microsac nozzle, with cylindrical holes, and therefore inclined to cavitate. The experimental results available for the validation purpose comprised measurements of mass flow rate and spray momentum flux, which correctly combined provide also fundamental information such as discharge coefficient, nozzle exit effective velocity and area contraction. The model was proved to be able of 
reproducing the experimental results with high degree of confidence and, through the exploration of the internal flow, allowed the explanation of widely reported experimental findings related to cavitation phenomena: the mass flow choking induced by cavitation and the increment of effective injection velocity.

\section{KEYWORDS}

Cavitation, Diesel, injection, nozzle, mass flow choking.

\section{LIST OF NOTATION.}

\section{NOMENCLATURE}

$a$ : speed of sound

A: area

$A_{\text {eff: }}$ outlet effective area

$A_{o}$ : outlet area

$B P$ : back pressure

$C_{a}:$ area coefficient

$C_{d}$ : discharge coefficient

$C_{M}$ : momentum coefficient

Co: courant number

Co acoustic: acoustic courant number

$C_{v}$ : velocity coefficient

$D_{\text {eff: }}$ effective diameter

$D_{i}$ : diameter at the orifice inlet

$D_{o}$ : diameter at the orifice outlet 
$K$ : cavitation number $K=\frac{P_{i n j}-p_{s a t}}{P_{i n j}-P_{b a c k}}$

k-factor: orifice conicity factor

$L$ : orifice length

$\dot{m}_{f}$ : mass flow

$\dot{M}_{f}:$ momentum flux

$p$ : pressure

$P_{\text {back }}:$ discharge back pressure

$P_{i n j}:$ injection pressure

$p_{\text {sat }}$ : vaporisation pressure

$R_{o}$ : outlet radius

$r$ : rounding radius at the inlet orifice

$t$ : time

$u$ : velocity

$u_{\text {eff: }}$ effective velocity

$u_{t h}$ : theoretical velocity

$u_{y}$ : velocity in the y direction

\section{GREEK SYMBOLS:}

$\gamma$ : vapour mass fraction

$\Delta P$ : pressure drop, $\Delta P=P_{i n j}-P_{\text {back }}$

$\Delta t:$ time step

$\Delta x:$ cell size

$\mu$ : fluid viscosity 
$\mu_{l}$ : liquid viscosity

$\mu_{v}$ : vapour viscosity

$\rho$ : fluid density

$\rho_{l}$ : liquid density

$\rho_{\text {lsat }}$ liquid density at saturation

$\rho_{l}{ }^{o}$ : liquid density at a given temperature condition

$\rho_{v s a t}:$ vapour density at saturation

$\rho_{v}$ : vapour density

$\Psi$ : fluid compressibility

$\Psi_{l}$ : liquid compressibility

$\Psi_{v}$ : vapour compressibility

\section{SUBSCRIPTS:}

exp: experimental

model: numerical simulation

\section{INTRODUCTION}

It is well known that the characteristics of the internal nozzle flow have a strong impact on the spray and its atomization characteristics [1-5]. This is particularly true when cavitation occurs in the holes of fuel injector nozzles under the high injection pressures at which operate modern Diesel engines. Nevertheless, due to extremely small geometry of the holes, whose length is about $1 \mathrm{~mm}$ and whose diameter ranges from about 0.1 $\mathrm{mm}$ to $0.2 \mathrm{~mm}$ for most automotive Diesel engines, experimental and computational studies of the flow inside the real-size nozzle are still not satisfactory. From the point of view of the experimental research, although useful information has been obtained from 
large scale nozzle experiments, scale effects have been recognized to be very important $[6,7]$. As a clear example, cavitation structures differ from large scale nozzles (clouds of bubbles) to real scale nozzles (cavitation pockets) [6].

As far as computational studies is concerned, two-phase approaches involving cavitation phenomena are not a mature art as is the case with one-phase calculations and it still needs improvements in order to increase the confidence in the results.

Following, the major experimental findings on the influence of cavitation on internal nozzle flow are summarized, as well as cavitation modelling approaches and limitations. It is widely known that cavitation induces to a mass flow collapse [7-10] and, indeed, this mass flow choking has been used for several researchers to determine the inception of cavitation by a non-intrusive way. Nevertheless, the reasons of mass flow chocking and its consequences on the flow are not completely justified yet.

Cavitation generates vapour into the flow which in turn increases the maximum velocity in the liquid core. It is believed, but not yet probed, that velocity increases for two reasons when the fluid is cavitating:

- On the one hand, if there is vapour along the wall, friction losses will be reduced, thus allowing the velocity of the liquid phase to increase [3]. As it will be discussed in the analysis section of this paper, the diminution of friction losses can be justified by the big difference in viscosity between vapour fuel and liquid fuel, and thus, inducing to a more square velocity profile across the hole channel.

- On the other hand, when the fluid is cavitating the liquid phase (with high density) cannot fill the entire channel, and so, the effective diameter is reduced compared to the geometrical one because of the zones occupied by the vapour 
(low density) $[3,6]$. It is important to remark that the density ratio between liquid and vapour reaches values of several thousands.

Furthermore, cavitation increases spray cone angle and so it is expected to improve the air-fuel mixing process $[11,12]$. Nonetheless, the reasons still remained unclear. Experimental investigations of cavitating nozzle flow have been often accompanied by numerical modelling [10, 12-16]. The use of computational fluid dynamics tools (CFD) to predict internal nozzle flow has increased in the last decade due to the reduction of lead times, the possibility to study systems where controlled experiments are difficult to perform and the unlimited level of details provide by numerical simulations without any type of restriction. In modern Diesel engines the liquid fuel injection pressure has been increased above $180 \mathrm{MPa}$. In such adverse conditions, nozzle flow models based on empirical correlations are likely to become increasingly inaccurate and full three dimensional nozzle flow solutions based on the governing Navier-Stokes equations are required. Due to the complexity of cavitation phenomena, which involves two phases with very different properties in terms of density or viscosity, a compromise between model stability and level of accuracy is needed.

In numerical simulations of internal nozzle flow, three approaches are mainly considered:

- Interface tracking methods. These models only solve the physical equations in the liquid phase and assume that the pressure in cavities is equal to that of the vapour pressure of the liquid. In this way, the liquid-vapour interface is explicitly tracked in conjunction with a wake model to handle the cavity closure region and predict the shape of the cavity. Interface tracking models normally use grid regeneration (adaptive grids) to conform to the cavity shape and has been demonstrated to work reasonably well for steady state sheet cavitation [17], 
but require extensive reworking for cases of bubble growth, bubble collapse and bubble detachment.

- Two-fluid nozzle flow models, which treat the liquid and vapour phases separately, i.e. two sets of governing equations (one for each phase) are solved and interaction between the phases are modelled by an additional source term. This models can be grouped in two mainly categories: Eulerian-Eulerian models $[18,19]$ and Eulerian-Lagrangian models [20]. The Eulerian-Eulerian models are based on the transport of volume fraction, and a source term representing phase transition that is governed by the difference between local pressure and vapor pressure. Cavitation phenomenon is assumed to take place due to the presence of bubble nuclei within the liquid phase, which can grow or collapse and are taken into account by the Rayleigh's simplified bubble dynamics equation.

On the other hand, the Eulerian-Lagrangian models consider liquid as the carrier phase in a Eulerian frame of reference and vapor bubbles as the dispersed phase using a Lagrangian frame of reference, using bubble parcels to simulate the entire population of actual vapour bubbles. In order to start the cavitation phenomenon, nuclei are artificially created defining the size of each nucleus from a probability density function. For these models the bubble dynamics is calculated using the complete Rayleigh-Plesset equation.

- Continuum nozzle flow models or homogeneous equilibrium models [21-23], henceforth mentioned as HEM, on which it is assumed that liquid and vapour phases are always perfectly mixed in the sub-grid cell and also the temperature is constant. These homogeneous equilibrium models are most widely used and have various forms depending on how the equation of state and pressure 
equation are formulated. In these models, an equation of state relating pressure and density (barotropic equation) allows the calculation of the growth of cavitation to be done.

Previous works in the field have modelled cavitating liquid, but not the ambient air in the combustion chamber due to the difficulty of resolving three phases while maintaining reasonable times. More recently, OpenCFD $®$ Ltd [24] developed a code handling liquid, cavitating liquid and ambient air. The purpose of the code was to simulate cavitating Diesel fuel injected into a chamber filled with air. Even though the code can have others uses, simulating Diesel injections was its original purpose [23]. A simpler but most robust code was also developed as part of the previously mentioned three phase code for cavitating nozzles which is implemented in the version 1.5 of OpenFOAM ${ }^{\circledR}[24]$. This last one has been the model used for the present investigation. Although a validation of the code can be found in the literature for small pressure drop conditions [25], its validation at high pressure drops and for small orifices which are both typical characteristics of Diesel injector nozzles has not been done yet. The aim of this paper has been to evaluate the potential of the code to treat cavitation in such conditions by comparing the results from numerical simulations with experimental measurements. One of the main contributions of the present investigation and what makes it different from previous works in the literature is the consideration of extended experimental data for validation purpose: mass flow together with momentum flux and effective injection velocity at the nozzle exit, which are both important features describing the behaviour of the inner nozzle flow. Conventional publications in the area take into account qualitative parameters as cavitation morphology or discharge coefficient. Nevertheless, momentum flux, aside from being one of the most important parameter that controls the air-fuel mixing process in the spray [26], provides, in 
combination with mass flow, basic information such as effective injection velocity or effective injection section [3], which allow the study of the internal flow to be done in a non-intrusive way, without the needed of visualizing it. The results obtained from simulations and their comparison with available experimental data showed that the model is able to predict with enough level of confidence the behavior of the fluid in such conditions. Therefore, the main physical process taking place such as mass flow choking induced by cavitation and the increase of effective injection velocity owing to the friction losses reduction, have been observed and explained with the help of the code.

As far as the structure of the paper is concerned, it has been divided in 8 sections. First of all, in section 2, a description of the CFD approach is made, where the equations governing the model and how they are solved are explained in detail. Secondly, the nozzle geometry characteristics and the experimental data available for validation are presented in section 3. The derivation of three important one-dimensional parameters describing the nature of the inner flow and the experimental operating conditions are made in section 4 and 5 respectively. Following, in section 6, the particularities of the mesh used for the computational study, fluid properties and simulation conditions are described. The numerical results obtained from a multi-hole nozzle simulation and their comparison with those coming from the experimental facilities are presented and discussed in section 7. Finally, the main conclusions of the investigation are drawn in section 8 .

\section{DESCRIPTION OF THE CFD APPROACH}

\subsection{Model equations.}


In section 1 was stated the two main approaches for modelling cavitation phenomena. In the case which we are dealing with, the use of a HEM with a barotropic equation of state seems to be the most suitable method due to high pressures and velocities that occur in diesel injectors. In the code, it is assumed that liquid and vapour are always perfectly mixed in each cell and the compressibility of both phases is taken into account.

A common barotropic equation of state is the non-equilibrium differential equation:

$$
\frac{D \rho}{D t}=\Psi \frac{D p}{D t}
$$

with $\Psi$, the compressibility of the mixture, which is the inverse of the speed of sound squared:

$$
\Psi=\frac{1}{a^{2}}
$$

This equation can be introduced directly in the continuity equation to formulate a pressure equation. The equation of state should be consistent with the liquid and vapour equations of state both at the limits when there is pure liquid or pure vapour, and also at intermediate states when there is a mixture of them. Both phases can be defined with a linear equation of state:

$$
\begin{aligned}
& \rho_{v}=\Psi_{v} \cdot p \\
& \rho_{l}=\rho_{l}^{0}+\Psi_{l} \cdot p
\end{aligned}
$$

To determinate the amount of vapour in the fluid, the parameter $\gamma$ is used. It is worked out as:

$$
\gamma=\frac{\rho-\rho_{l s a t}}{\rho_{v s a t}-\rho_{l s a t}}
$$

where $\quad \rho_{v s a t}=\Psi_{v} \cdot p_{\text {sat }}$ 
It can be seen that in a flow with no cavitation $\gamma=0$, whereas for fully cavitated flow $\gamma=1$. In Eq. (6), $\Psi_{v}$ is the compressibility of the vapour.

The density of the mixture is calculated taking into account the amount of vapour in the fluid $(\gamma)$ together with a correction term based on the pressure (mixture's equilibrium equation of state):

$\rho=\gamma \cdot \rho_{v}+(1-\gamma) \cdot \rho_{l}+\psi\left(p-p_{s a t}\right)=(1-\gamma) \cdot \rho_{l}^{0}+\left[\left(\gamma \cdot \psi_{v}+(1-\gamma) \cdot \psi_{l}\right)-\psi\right] \cdot p_{s a t}+\Psi \cdot p$

with $\quad \rho_{l}^{0}=\rho_{l, s a t}-\Psi_{l} \cdot p_{\text {sat }}$

As far as the mixture's compressibility is concerned, it is modelled by a simple linear model:

$\Psi=\gamma \cdot \Psi_{v}+(1-\gamma) \cdot \Psi_{l}$

with $\Psi_{1}$ equal to the compressibility of the liquid.

Despite of there are models which describe the compressibility of the mixture in a more physical way (Wallis or Chung), a linear model was used basing it choice on the convergence of the results and their stability.

As done for compressibility, it is possible to obtain the viscosity of the mixture with a linear model:

$\mu=\gamma \cdot \mu_{v}+(1-\gamma) \cdot \mu_{l}$

The methodology used by the solver starts solving the continuity equation for $\rho$ (Eq. (11):

$\frac{\partial \rho}{\partial t}+\nabla(\rho \cdot u)=0$

The spatial discretization of $\rho$ in the divergence term $\nabla(\rho \cdot u) \nabla(\rho \cdot u)$ is made by using a Gauss upwind numerical scheme. It is well known that a first-order scheme leads to a much stable numerics, but it is more sensitive to mesh coarseness and it normally 
presents more numerical diffusion than a second-order scheme. Nevertheless, because of large gradients in pressure and density present in Diesel nozzles, stability is a main argument and so, an upwind scheme has been used. Numerical diffusion and gridindependence have been controlled by an adequate-mesh refining done in a previous set up of the model where a mesh sensitivity study was performed.

Despite of a MUSCL scheme was used by Kärrholm et al. [25] to validate the code for small pressure drops, in diesel injector nozzles at high injection pressures and high flow velocities this numerical scheme provided an unstable solution. As can be seen in Figure 1, where the mass flow of a one-hole nozzle is depicted as a function of time for three different divergence schemes (TVD MUSCL, TVD Van Leer and Gauss upwind), the MUSCL scheme shows important instabilities, even with negative mass flows, so the use of this scheme for the present investigation was ruled out. Comparing all them, Gauss upwind seems to be the most stable and so the most suitable scheme for solving for the divergence terms in the continuity equation.

The value of $\rho$ obtained, is used to determine preliminary values for $\gamma$ and $\Psi \Psi$ by means of Eq. (5) and Eq. (9), and also, for solving momentum equation (Equation 12) which is used to get the matrices used to calculate the pressure-free velocity, $u$ :

$$
\frac{\partial(\rho \cdot u)}{\partial t}+\nabla(\rho \cdot u \cdot u)=-\nabla p+\nabla\left(\mu_{f} \cdot \nabla u\right)
$$

The same Gauss upwind numerical scheme is used for the velocity divergence scheme and a Gauss linear corrected scheme (second order) is used for the Laplacian term discretization.

Following, an iterative PISO algorithm is used to solve for $p$ and correct the velocity to achieve continuity. The equation solved for the PISO loop is the continuity equation transformed into a pressure equation by use of the equation of state (Eq. (7)): 


$$
\frac{\partial(\Psi \cdot p)}{\partial t}-\left(\rho_{l}^{0}+\left(\Psi_{l}-\Psi_{v}\right) \cdot p_{s a t}\right) \cdot \frac{\partial \gamma}{\partial t}-p_{s a t} \cdot \frac{\partial \Psi}{\partial t}+\nabla(\rho \cdot u)=0
$$

Once continuity has been reached, the properties $\rho, \gamma$, and $\Psi$ are updated by means of equations (7), (5) and (9) respectively which are taken into account to solve again momentum equation, and so, repeating the algorithm until convergence.

The time step is limited by both the Courant number and the acoustic Courant number, defined as:

$$
\begin{aligned}
& C o=\max \left(\frac{|u|}{\Delta x}\right) \Delta t \\
& C o_{\text {acoustic }}=\max \left(\frac{1}{\sqrt{\Psi} \Delta x}\right) \Delta t
\end{aligned}
$$

The Courant number was chosen to be limited to 0.4 , while the acoustic Courant number was limited to 12.5 . Both values have been chosen after an extended study about the influence of these parameters on the results accuracy, taking also into account the computational cost. As indicates Equation 14, the time step decreases as the Courant number decrease, so if this parameter is very small, computational cost can increase considerably. However, if the Courant number is sufficiently high, the accuracy of numerical results provided by the code can get worse. Similar analysis can be done for the acoustic Courant number.

Taking into account the important velocities that are normally found in Diesel applications (in the present investigation up to $500 \mathrm{~m} / \mathrm{s}$ ) and the small size of the cells as a result of a preliminary study that allowed the appropriate mesh fineness to be chosen, time steps used are around $10^{-9} \mathrm{~s}$.

\subsection{About the advisability of using turbulence approach.}


One can find in the literature some contradictories thoughts about the convenience of modelling turbulence when cavitation is present in the inner nozzle flow. On one hand, Desantes et al. [26] demonstrated that, despite of using high pressure drops, the fact of having so small diameters entails that the flow could be considered as transitional between laminar and turbulent. This analysis was made by studying the discharge coefficient behaviour against Reynolds number. In the same sense, Faeth et al. [27] has shown that turbulence does not have time to fully develop due to the short length of the orifice (around $1 \mathrm{~mm}$ ). On the other hand, several experimental investigations and numerical studies have shown a significant effect of turbulence on cavitating flows [18, 28, 29]. According to Ruiz and He [30], turbulence in unsteady cavitating flows cannot be modelled as typical turbulence. Further research is needed in order to understand the physical processes governing cavitation-turbulence interactions.

In this research, the authors assume, as a first approximation, that cavitation is the main process taking place in the holes of a Diesel injector and so, turbulence does not play a major role on the flow features [31]. This assumption seems to be appropriate in the very low pressure regions, that is, near inlet hole corners, where pressure decreases dramatically. Furthermore, turbulence models introduce and added complication in any flow calculation and their validity is limited.

\section{EXPERIMENTAL FACILITIES}

In this section, the injection system, the nozzle characteristics, fluid properties and the experimental test benches for the hydraulic characterization of the nozzles are described. 


\subsection{Injection system, nozzles and fluid properties}

The injection system used throughout this study is a conventional Common Rail Fuel Injection system which makes it possible to reach high and relatively constant pressure values (up to $160 \mathrm{MPa}$ ) [32]. The injector where the nozzles were mounted is a second generation solenoid Bosch injector. With the aim of obtaining stabilized conditions without disturbing influences of needle lift, a very large energizing time of four milliseconds has been used.

A six-orifices microsac nozzle was used for this study. In order to determine the nozzle's exact internal geometry a methodology described by Macián et al. [33] was used. The methodology is based on the use of a special type of silicone in order to obtain internal moulds of the nozzles. Once the moulds have been obtained, pictures of them are taken with a scanning electron microscope (SEM). A picture of this facility is depicted in Figure 2. The internal characteristics obtained by means of this methodology are reported in Table 1 where the degree of conicity involving inlet and outlet diameters is evaluated by the $k$-factor, defined as:

$$
k-\text { factor }=\frac{D_{i}-D_{o}}{10}
$$

As can be seen from the table, $k$-factor for the nozzles is 0 . Thus, the nozzle is cylindrical and so, inclined to cavitate [11]. The value of $r$ in Table 1, is the rounding radii at the inlet orifice, which together the $k$-factor are the most important factors inducing nozzles to cavitate $[11,31]$. Obviously, geometrical values correspond to the mean value of all orifices. The fluid used for the experimental was a Repsol CEC RF06-99 fuel, and some of its characteristics are depicted in Table 2. 


\subsection{Injection Rate Meter}

Tests of injection rate were carried out with an Injection Rate Discharge Curve Indicator (IRDCI) commercial system. This device makes it possible to display and record the data that describe the chronological sequence of an individual fuel injection event, with an uncertainty value of $1.5 \%$. The measuring principle used is the Bosch method rate meter [34], which is a measurement device designed to obtain the injection rate from pressure waves created inside a fuel-filled tube. The fuel discharge produces a pressure increase inside the tube which is proportional to the increase in fuel mass. The rate of this pressure increase corresponds to the injection rate [35]. A pressure sensor detects this pressure increase and an acquisition and display system further processes the recorded data for obtaining the mass flow rate.

\subsection{Spray Momentum test Rig}

With this experimental equipment it is possible to determine the impact force of a spray on a surface. This force is equivalent to the spray momentum flux. Figure 3 shows a picture of the momentum test rig. In that test rig, the sprays are injected into a chamber that can be pressurized with nitrogen up to $10 \mathrm{MPa}$, in order to simulate pressure discharge conditions that are representative of real pressure conditions inside the engine combustion chamber during the injection process. The impact force is measured with a calibrated piezo-electric pressure sensor in order to measure force which is placed at 5 $\mathrm{mm}$ from the hole exit, as shown in the zoomed image of Figure 3. This equipment provides the momentum flux measurement with an uncertainty of around $1.8 \%$. The sensor frontal area and position are selected so that spray impingement area is much smaller than that of the sensor. Under this assumption, and due to the conservation of momentum in axial direction, the force measured by the sensor will be the same as the 
momentum flux at the hole outlet or at any other axial location, since the pressure inside the chamber is constant and surrounds the entire spray, and fuel deflected is perpendicular to the axis direction [3].

\section{PARAMETERS DESCRIBING THE INNER NOZZLE FLOW}

Cavitation in a Diesel nozzle appears at the inlet of the nozzle hole. In this region, and due to the strong change in cross-section and flow direction, the boundary layer tends to separate from the hole wall and a so-called "vena contracta" is established. As a consequence, a recirculation zone appears between the "vena contracta" and the orifice wall. In this zone there is a pressure depression due to the acceleration of the fluid. If the static pressure falls below vapour pressure then the phenomenon of cavitation will arises. A simplified sketch of this situation can be observed in Figure 4. Due to the complexity of the problem, it is difficult to choose which are the proper parameters to characterize the flow. The usual measured pressures are the injection pressure $P_{i n j}$ and the discharge backpressure $P_{b a c k}$. These two values will be used for calculation and analysis purposes. The pressure drop $(\Delta P)$ across the orifice will be calculated by subtracting $P_{b a c k}$ from $P_{i n j}$. This statement implies that the loss coefficients used throughout this paper will be representative of all losses between the injector inlet and the discharge chamber. In fact, most of the losses in the injection system are located inside the nozzle hole $[11,31,36]$.

From the mass flow and momentum flux some important considerations can be stated. Under cavitating conditions, the flow at the outlet hole section will have an arbitrary velocity profile, as well as a density profile with liquid and vapour zones. This situation is depicted in the Figure 5a. Under such conditions mass flow and momentum flux are defined as: 


$$
\begin{aligned}
& \dot{m}_{f}=\int_{A_{o}} u \cdot \rho \cdot d A \\
& \dot{M}_{f}=\int_{A_{o}} u^{2} \cdot \rho \cdot d A
\end{aligned}
$$

This complex flow configuration can be simplified, as can be seen in Figure 5b., considering that all the fluid is in liquid phase and it flows through an effective area, $A_{\text {eff, }}$, with a constant effective velocity, $u_{\text {eff }}$, so that mass flow and momentum flux keep the same value than in the actual situation. From such conditions, the following definitions for the effective velocity and effective area can be obtained:

$$
\begin{aligned}
& u_{e f f}=\frac{\dot{M}_{f}}{\dot{m}_{f}} \\
& A_{e f f}=\frac{\dot{m}_{f}^{2}}{\rho_{l} \cdot \dot{M}_{f}}
\end{aligned}
$$

The effective area is smaller than the geometrical one, since there are section losses due to the presence of vapour voids and the existence of non-uniform velocity profiles at the outlet section of the hole. If the effective area is considered as circular, an effective diameter, $D_{\text {eff, }}$ can also be defined.

On the other hand, by using Bernoulli's equation between the inlet $\left(P_{i n j}\right)$ and the outlet $\left(P_{b a c k}\right)$ of the nozzle hole, and assuming that the inlet velocity is negligible, it is possible to obtain the theoretical velocity at the outlet section, $u_{t h}$ :

$$
\begin{aligned}
& P_{i n j}=P_{b a c k}+\frac{1}{2} \rho_{l} \cdot u_{t h}{ }^{2} \\
& u_{t h}=\sqrt{\frac{2 \Delta P}{\rho_{l}}}
\end{aligned}
$$

With the outlet theoretical velocity, a theoretical mass flow is obtained by assuming a constant cross-section and density. A first non-dimensional parameter, the discharge 
coefficient $C_{d}$, is obtained by dividing the actual mass flow by the theoretical mass flow:

$$
C_{d}=\frac{\dot{m}_{f}}{A_{o} \cdot \rho_{l} \cdot u_{t h}}=\frac{\dot{m}_{f}}{A_{o} \sqrt{2 \cdot \rho_{l} \cdot \Delta P}}
$$

With the use of a theoretical momentum flux a new non-dimensional parameter, $C_{M}$, or momentum coefficient is defined:

$$
C_{M}=\frac{\dot{M}_{f}}{A_{o} \cdot \rho_{l} \cdot u_{t h}{ }^{2}}=\frac{\dot{M}_{f}}{2 \cdot A_{o} \cdot \Delta P}
$$

In order to describe the inner flow in more detail, losses included in the discharge coefficient could be divided into two parts, as Eq. (25) shows: the velocity coefficient, $C_{v}$, which takes into account the loss in the velocity term, and the area coefficient, $C_{a}$, which takes into account the loss of section and density variations. Accordingly, the velocity coefficient, $C_{v}$, is defined as the relationship between effective velocity and theoretical velocity, Eq. (26), whereas the area flow coefficient, $C_{a}$, is defined as the effective area divided by the geometrical area, Eq. (27).

$$
\begin{aligned}
& C_{d}=C_{v} \cdot C_{a} \\
& C_{v}=\frac{u_{e f f}}{u_{t h}} \\
& C_{a}=\frac{A_{e f f}}{A_{o}}=\frac{D_{e f f}^{2}}{D_{o}^{2}}
\end{aligned}
$$

\section{EXPERIMENTAL OPERATING CONDITIONS}

Mass flow rate and momentum flux measurements were performed at different injections conditions which are summarized in Table 3. As can be seen in the table, tests 
were conducted at two values of injection pressure, i.e. nozzle inlet pressure of $30 \mathrm{MPa}$ and $80 \mathrm{MPa}$. For each one of them, four different backpressures were tested: $9 \mathrm{MPa}, 7$ $\mathrm{MPa}, 5 \mathrm{MPa}$ and $3 \mathrm{MPa}$. As explained in the introduction, the aim pursued was to create different cavitation intensity in order to evaluate the potential of the numerical model to reproduce the experimental results. Also to explain or clarify some experimental findings related to cavitation is expected from the theoretical model. For all the injection conditions, mass flow rate and momentum flux measurements were used to obtain the effective velocity and the three non- dimensional flow parameters described above.

\section{NOZZLE MESH DESCRIPTION AND SIMULATION CONDITIONS}

Because of nozzle symmetry, the domain of calculations has been reduced to $1 / 6\left(60^{\circ}\right)$ of the total nozzle. In Figure 6 the mesh used is depicted. The geometry faithfully keeps the geometrical parameters in Table 1, which, as established in section 3, are the mean values of all orifices. In order to compare with stabilized flow conditions of mass flow and momentum flux, the geometry representing of fully needle lift conditions (i.e. 250 $\mu \mathrm{m})$ has been modelled $[5,36]$. The computational domain was properly discretized in cells. As far as the structure of the grid is concerned, a partly structured grid that follows as much as possible the direction of the flow (as shown in the grid depicted in Figure 6), and a small unstructured zone, just at the orifice entrance (noticeable in the zoomed grid in Figure 6), was used. In previous studies [31], it was found that the partly structured grid performed better from the point of view of the stability and convergence rate. In addition, the large gradients that occur at the rounded orifice inlet are better captured with this type of mesh, since it follows the flow direction and creates less numerical diffusion. As it is known that the first cavitation bubbles appear at or just after the nozzle rounding, it was deemed necessary to refine particularly. 
Preliminary CFD Diesel nozzle calculations were done to allow the choice of the most appropriate mesh fineness for the calculations. Other important considerations about the cell size and meshing process from other authors in the literature about the cell size and meshing process were also taken into account $[15,16,19,20,22,23]$. Figure 7 shows some results of the study done to choose the most suitable cell size in multihole nozzles. The mesh chosen (with almost 400000 cells) corresponds to a cell size of $4 \mu \mathrm{m}$ in the orifice core (Di/42.5), varying to a minimum of $0.8 \mu \mathrm{m}$ in the wall. In order to accurately capture the gradients of pressure, density and viscosity expected in the near nozzle wall, which is the most critical zone of the orifice and when cavitation is expected to occur, the boundary layer is made up of 14 layers with cell sizes ranging from $0.8 \mu \mathrm{m}$ to $4 \mu \mathrm{m}$ gradually.

As far as the fluid properties used for simulations is concerned, properties of a Repsol CEC RF-06-99 fuel at a temperature of $20^{\circ} \mathrm{C}$ at which the experiments were performed are used. The liquid compressibility has been taken from measurements of the sound speed in Diesel fuel. The vapour properties have been obtained for a similar fuel from Peng Kärrholm [23, 25].

Regarding to the pressure operating conditions used for simulations, the injection pressures $\left(P_{i n j}\right)$ and backpressures $\left(P_{b a c k}\right)$ are given in Table 3 together with the experimental conditions.

Transient calculations of around $375 \mu$ s were performed which, as it will be seen in section 7 , is enough to obtain a stable solution. The convergence criteria used for the calculations are twofold: on the one hand, residuals for all equations have to reach a value of $10^{-7}$ at least; on the other hand, mass flow has to be as much stabilized as possible. As an example of the time consuming, the simulation $P_{i n j}=80 \mathrm{MPa}-P_{\text {back }}=5$ 
MPa lasted 6 days using parallel simulation (4 process) on an Intel@ Xeon E5405 @ 2 GHz, Quadcore 8 Gb RAM.

\section{NUMERICAL AND EXPERIMENTAL RESULTS}

\subsection{Cavitation appearance}

In Figure 8, and as an example of cavitation behaviour, the vapour field evolution between $360 \mu$ s and $371 \mu$ s microseconds is shown for the injection condition $P_{i n j}=80$ $\mathrm{MPa}-P_{\text {back }}=3 \mathrm{MPa}$. Images showed are 1 microsecond apart and the running time is depicted at the bottom of each sample. In those pictures, dark zones correspond to vapour phase fraction, and thus, low density, whereas white zones are those occupied by pure liquid. As can be seen, the vapour field showed, what could be considered a cycle of a cyclical process, where a large vapour "bubble" formed along the upper wall of the nozzle. The cavitation shape was not stable. The cavity life cycle provided by the model follows the stages identified by others researchers in the literature, either experimentally or numerically $[16,22,38,39]$. As they did, it can be identified the following phases in the cyclic behaviour of cavities: formation and growth, collapse and break-off. In that figure, the formation and growth can be observed from $360 \mu$ s to $368 \mu \mathrm{s}$. The asymmetry found is considered normal taking into account that the liquid enters the orifice mainly by the upper part of the nozzle and, therefore, the flow detachment and recirculation zone, which is, as it is well known, the origin of cavitation phenomena, take place in the inlet upper corner region of the hole. As will be shown in section 7.2.3, cavitation has a strong influence on the velocity profile at the hole exit, so continuous changes of vapour distribution induced by cyclic behavior force to a continuous changes of the velocity profile, and therefore in the subsequent air-fuel mixing process in the combustion chamber. 


\subsection{Numerical and experimental results comparison}

\subsubsection{Mass flow rate}

In Figure 9, the mass flow obtained from experiments and simulations is depicted for all injection conditions against pressure drop $\left(\sqrt{\Delta P}=\sqrt{\left(P_{\text {inj }}-P_{\text {back }}\right)}\right)$. In the upper part of the figure, the results obtained for $P_{i n j}=30 \mathrm{MPa}$ are shown for the backpressures of 9MPa, $7 \mathrm{MPa}$, 5MPa, and 3MPa, both experimentally and numerically. Additionally, results from simulations with backpressures of $1 \mathrm{MPa}$ and $0.1 \mathrm{MPa}$ has been added to the graph. In this graph the time-averaged vapour fields for all conditions in the symmetry plane, have been added in Figure 9. In the bottom part of the Figure, a comparison in the same terms is made for $P_{i n j}=80 \mathrm{MPa}$ and backpressures of $9 \mathrm{MPa}, 7$ $\mathrm{MPa}, 5 \mathrm{MPa}$, and 3MPa. Different aspects can be noticed from the results:

From the experimental values, as shown in the figure, for $P_{i n j}=30 \mathrm{MPa}$, the mass flow rate increases proportionally with the root of pressure differential until the point where it stabilizes. At this point, what is called "choked flow" occurs, and pressure conditions needed to arrive to this situation are named critical cavitation conditions. In fact, the detection of mass flow choking beginning is normally used to detect cavitation by a non-intrusive way in real nozzles, because of the difficulties of taking direct information about the internal flow $[3,9,10,11,16]$. For $P_{i n j}=80 \mathrm{MPa}$, the flow is always choked, remaining unchanged whichever the backpressure. In this case, due to experimental limitations, it was not possible to use higher backpressures in order to detect critical cavitation conditions, or characterized the mass flow rate in non-cavitating conditions. In simulations results, the mass flow rate obtained is the time-averaged during last 175 microseconds (62 times the time needed by a fluid particle to cover the whole orifice length). It is calculated by integrating equation (17) in the outlet section of the orifice, and multiplying by six, to consider the total mass flow rate of the nozzle. As it can be 
seen, it not only follows the same behavior shown by the experimental data but also, in quantitative terms, the predictions of the model are quite close to the experimental values. On one hand, for low injection pressures (30 MPa) the transition from noncavitating condictions to cavitating conditions is captured with high level of accuracy and the differences in mass flow rate are not higher than $1 \%$. On the other hand, in the case of $80 \mathrm{MPa}$ of injection pressure, although, as in the experimental case, the mass flow is choked for all conditions, the level of approaching to the experimental values is lower than in the previous case. In fact, the error is around $4 \%$.

The time-averaged vapour fields for Pinj= $30 \mathrm{MPa}$, show that cavitation intensity is higher as the backpressure decrease. In the case of discharge pressures of 5, 7 and 9 $\mathrm{MPa}$, the cavitation detected is incipient, and a zoomed image of the orifice entrance has been used instead of a full-image of the hole. One important conclusion can be drawn if computational mass flow rate results are compared with vapour fields: a first evidence of cavitation can be seen for a backpressure of $9 \mathrm{MPa}$ where a small zone with vapour can be seen just in the upper rounding radii at the orifice inlet. However, mass flow collapse does not appear until the discharge pressure is decreased to $5 \mathrm{MPa}$. This fact implies that, although cavitation critical conditions are close to cavitation inception, rigorously speaking, cannot be considered as the point (or conditions) at which cavitation starts.

These results agree with some other experimental investigations in the literature [40, 41] where bubbles from cavitation are visualized, coming out the orifice, for a pressure difference smaller than that of the critical conditions.

As stated before, all the simulations performed at $\mathrm{P}_{\text {inj }}=80 \mathrm{MPa}$ are at cavitating conditions, remaining constant the mass flow and showing vapour bubbles along the upper surface of the orifice wall. The pressure conditions simulated are far from critical 
cavitation conditions, so the differences found in the amount of vapour phase were expected.

In order to explain the reasons of the mass flow collapse, the internal nozzle flow behavior in terms of static pressure has been examined just in the section after the rounding radius and, obviously, by means of the code. In Figure 10, the pressure areaaveraged in the inlet section of the orifice for all injection conditions is plotted against root of pressure difference. In the upper part, the evolution of that mean pressures at the throat for the injection pressure of $P_{i n j}=30 \mathrm{MPa}$ and varying the discharge pressure are shown. At the bottom, the results related to the injection pressure $P_{i n j}=80 \mathrm{MPa}$ are depicted. If Figure 9 and Figure 10 are compared, a clear conclusion can be stated: looking at the results for $30 \mathrm{MPa}$, one can see that for the operating conditions where the mass flow is not choked, i.e. between $9 \mathrm{MPa}$ and $5 \mathrm{MPa}$, the pressure area-averaged at the throat decreases. For backpressures lower than $5 \mathrm{MPa}$, for which the mass flow rate does not increase further, the pressure at the throat keeps constant in a value of 8.5 MPa. For $P_{i n j}=80 \mathrm{MPa}$, the mean pressure is constant for all conditions with a value of $24 \mathrm{MPa}$. As a conclusion, it can be stated that, the reason of mass flow choking is the establishment of a constant pressure in the throat (orifice inlet) where there are cells (zones) with vapour pressure (just in the zone occupied by vapour, i.e. near the wall) and others, around of the orifice core, where pressures are much higher. So, in choking conditions the mass flow rate is controlled by the pressure drop between nozzle inlet (injection pressure) and the pressure at the orifice inlet, where cavitation has appeared. In that situation, mass flow rate is not further a function of the pressure drop over the nozzle but of the pressure drop between nozzle inlet and the hole throat. The explanation of the mass flow rate choking is easy if we consider Bernoulli's equation 
between nozzle inlet and orifice throat to calculate the mass flow rate along the nozzle, and considering, as it is compulsory, mass flow conservation along the orifice.

\subsubsection{Momentum flux, injection velocity and one-dimensional flow coefficients}

In Figure 11, the time-averaged computational and experimental results of momentum flux and effective velocity are plotted against the root of pressure difference. Effective velocity has been worked out by applying equation (19). Results belonging to the injection pressure of $30 \mathrm{MPa}$ are depicted on the left, and those represented on the right come from the injection pressure of $80 \mathrm{MPa}$. Each point in the graphs represents a different backpressure. As experimental and numerical results show, and opposite to mass flow, momentum flux does not present any collapse. This result has been observed and discussed in other previous studies [3]. The agreement between experimental and numerical results is good, especially at low injection pressures, considering that there are experimental uncertainties linked to the determination of the real geometry, or needle deformation effects, which has not been considered for the computational study. In fact, needle deformation can lead to actual needle lifts higher than the needle's mechanical stroke, which in turn, influences the mass flow rate. Indeed, it is known that for high injection pressures, needle deformations can be of same order than needle lifts $[31,36]$. This effect should be further studied because it could be one of the reasons of the higher discrepancies found between the experimental and numerical results at high injection pressure, where the differences (lower-prediction) reach a value of around $9 \%$. Additional explanations to these differences are also given in section 7.2.3.

Owing to the increase of momentum flux when decreasing the discharge pressure and the mass flow collapse, taking into account equation (19), an increment in the effective velocity is expected (and observed) in the graph, at the bottom of the Figure 11. 
Although this result could be considered normal because of the increment in pressure difference, in Figure 12, where flow coefficients are represented against the root of pressure difference, it can be noted that, the increase in effective velocity when decreasing the backpressure (and so increasing cavitation intensity) is higher than the expected due to the increase in pressure drop. This result can be observed when looking at the velocity coefficient, $C_{v}$ which is easily derived by combining the effective velocity and the theoretical one by means of Eq. (26). Indeed, this coefficient experiences an increase with cavitation intensity. This result has been observed experimentally before $[3,11]$ but in this case, has also been corroborated by numerical results. The increase in velocity coefficient is gradual for the case of $P_{i n j}=30 \mathrm{MPa}$, starting from $\mathrm{P}_{\text {back }}=5 \mathrm{MPa}$, at which cavitation begins spreading along the walls, as was observed in previous section. For $P_{i n j}=80 \mathrm{MPa}$ (Figure 13), the velocity coefficient, and thus effective velocity, experiences a more important increment from the beginning than in previous case, as the backpressure decrease. In this case, as seen before, the hole is always cavitating and mass flow is always choked. The increment of injection velocity as a consequence of cavitation phenomena will be discussed in more depth in section

\subsection{3.}

As stated before, other factors describing the flow across the nozzle are the discharge coefficient, $C_{d}$ and the flow contraction coefficient, $C_{a}$. As was established in section 4 , the discharge coefficient, $C_{d}$, is evaluated by means of Eq. (23), and, the contraction coefficient, $C_{a}$, is obtained from $C_{d}$ and $C_{v}$ by using Eq. (25). As a consequence of the quite good approximation between experimental and computational results in terms of mass flow rate, the discharge coefficient obtained numerically agree with those provided by the experiments, and obviously, with the same level of confidence as the mass flow rate results discussed above. In physics terms, and as a consequence of the 
mass flow collapse and Eq. (23), the discharge coefficient has a dramatic decrease with cavitation development. As far as the contraction coefficient is concerned, its decrease with cavitation intensity is captured by the model with high level of accuracy, either for $P_{i n j}=30 \mathrm{MPa}$ or $P_{i n j}=80 \mathrm{MPa}$ of injection pressure. Taking into account the complexity of simulating cavitation, results can be considered quite acceptable and thus, the model is able to provide results with high level of approximation of those obtained experimentally. It should be remarked that validation is made from two different points of view involving mass flow and momentum flux results which is not common in similar works that can be found in the literature.

Up to now, it has been seen that the model is able to reproduce the mass flow collapse and it has also allowed justifying it: the stabilization of the pressure area-averaged at the hole throat. Also, it has been seen above, that as was found experimentally, cavitation produces a considerable increment in the effective velocity. As was stated in the introduction section, it is believe that the presence of vapour in the near wall region originates a diminution of friction losses, which in turn, influences the velocity. In the following section the influence of cavitation on velocity profile is dealed successfully by means of an on-purpose numerical simulation.

\subsubsection{Influence of cavitation on velocity profile}

To study the influence of cavitation on the velocity profile, a nozzle with only one orifice and with axial symmetry has been used. This kind of geometry allows isolating the effect of cavitation from the disturbances originates by the asymmetry in the flow with the real six-hole nozzle considered for the present study. In fact, taking into account that the pressure inlet condition in the multi-hole nozzle configuration is placed in the upper part of the nozzle, the flow enters preferably from above and, as a consequence, the cavitation effects remain hidden under an important asymmetry 
induced by the geometry. To avoid that asymmetry, a one-hole nozzle has been modeled as the one showed in Figure 14 (at the top, on the left). For that geometry, two different simulations have been performed: on the one hand, a simulation aiming at inducing cavitation phenomena was performed by using an injection pressure and backpressure of $P_{i n j}=27.1 \mathrm{MPa}$ and $P_{b a c k}=0.1 \mathrm{MPa}$ respectively. On the other hand, a simulation with the intention of keeping the same pressure drop (and thus the same theoretical velocity), but avoiding cavitation phenomena, was performed by using an injection and backpressure of $P_{i n j}=39 \mathrm{MPa}$ and $P_{b a c k}=12 \mathrm{MPa}$ respectively. Vapor field timeaveraged is depicted for both simulations in Figure 14. For the first simulation cavitation has appeared and extended along the nozzle wall, by contrast in second simulation cavitation has not appear, as was expected. As in previous cases, black zones in the picture represent the area occupied to some degree by vapor. In that Figure, on the right, density and axial velocity radial profiles are depicted at the hole exit against the adimensionnalised radial coordinate (dividing by orifice radius), which takes a value of 0 in the orifice axis, and 1 in the wall. Results of the cavitating simulation are represented with continuous line and those of the non-cavitating simulation are depicted with pointed line. As can be seen in the density graph, for radial coordinate of around 0.7 , the density decreases from the liquid density value to the vapour density value, which means that the density experiences a decrease of about six thousand times as shown in Table 2. Although is not depicted, the viscosity behaves in a similar way, varying from the viscosity of the pure liquid to that of the pure vapour. In that case, taking into account Table 2, the variation in viscosity is of around six hundred times. As shown in section 2.1, the viscosity of the mixture is obtained by means of Eq. (10), which is a function of the vapour mass fraction. The consequences of the viscosity reduction can be noted in the velocity profiles depicted above the density profiles. As can be seen, the 
velocity profile in the cavitating flow is more squared as a consequence of the viscosity reduction in the vapour occupied zone. If the effective velocity is worked out by means of Eq. (19), the values obtained are $241.19 \mathrm{~m} / \mathrm{s}$ and $225.38 \mathrm{~m} / \mathrm{s}$ for the cavitating and non-cavitating case respectively. This result leads to a velocity coefficients values of $C_{v}=0.94$ and $C_{v}=0.88$. According to Eq. (19), the increment of effective velocity with cavitation is the reason because the momentum flux does not present any collapse despite of having the mass flow chocked. Obviously, in this particular modeled case where cavitation extend along the whole orifice wall, effects on effective velocity are more important than in the multi-hole case, where, as it was seen in Figure 8, the vapour collapses due to the use of higher backpressures and thus, it affects to a lesser extend the effective velocity.

\subsection{Future actions in progress in order to improve the model accuracy}

In order to improve the accuracy of the cavitation code, the authors believe that the following points have to be managed in future research activities:

- The possibility of including needle deformation effects. In fact, it is known that for high injection pressures, needle deformations can be of same order than needle lifts, and so, this effect should be further studied $[31,36]$. It would surely improve results at high injection pressures conditions at which deformations of the needle become non negligible.

- Effects of turbulence, studying the cavitation phenomena taking into account the turbulence effects by RANS or LES methods. The introduction of the turbulence effects could help to advance in the knowledge of the internal flow and resolve the issues that are still unclear. It does not expect important changes in the numerical results, but they can present some differences. For example, Figure 15 
shows a comparison of a preliminary RNG k- $\varepsilon$ simulation (RANS) against a laminar one at $\mathrm{P}_{\mathrm{inj}}=30 \mathrm{MPa}-\mathrm{P}_{\mathrm{back}}=7 \mathrm{MPa}$. As can be seen comparing both simulations, there are few differences in the vapour field averaged, since cavitation seems to be more developed in the turbulent case. As stated before, the use of RANS or LES methods (especially the last one) will be dealt with in the near future expecting to improve the accuracy of the code.

- The use of non-reflective boundary conditions at the nozzle exit. By this way, it would be possible to take into account pressure waves propagation. A typical NSCBC (Navier-Stokes characteristic boundary conditions) formulation seems to be the best approach for this kind of flow [22].

- As an alternative to the previous point, extended geometries (i.e. meshes) taking into account a part of the injection chamber could also result in better predictions. Indeed, the authors believe that the nature of the vapour structures provided by the code could be affected by a "numerical collapse" owing to the use of a rigorous pressure condition at the orifice outlet. The imposition of that boundary condition downstream of the orifice exit probably leads to a more extended cavitation and so, less friction in the hole, which in turn, leads to higher values of effective velocity and mass flow rate and so, predictions closer to the experimental results at high injection pressure.

\section{CONCLUSIONS}

From the present investigation the following main conclusions can be drawn:

- An extended validation of a code for modeling cavitation has been performed in diesel injector nozzles comparing the CFD results against experimental data, showing a deviation of around $7 \%$ between both results. In contrast to 
conventional publications, this validation covers mass flow, momentum flux, effective velocity and flow coefficients, so it can be considered as exclusive features on this type of works, which normally take into account qualitative parameters as cavitation morphology or, at the most, mass flow or discharge coefficient.

- Cavitation behavior predicted by the numerical simulations, showed a cyclic behaviour. A cavity life cycle was provided by the model following clear phases: formation and growth, collapse and break-off. The continuous changes in vapour distribution have a strong influence on the velocity profile at the hole exit, and therefore on the air-fuel mixing process in the combustion chamber.

- The mass flow choking induced by cavitation phenomena has been explored revealing that the reason of this collapse is a constant pressure at the throat. In addition, it has been demonstrated that, although critical cavitation conditions (c.c.c.) are very close to cavitation inception, cannot be considered as the point at which cavitation starts, since first vapour bubbles appear just before c.c.c.

- Finally, a comparison of a one-hole nozzle at cavitating and non-cavitating conditions has allowed studying and justifying the increase of injection velocity induced by cavitation. This velocity rise can be justified due to the reduction of viscosity as a consequence of the presence of vapour.

\section{ACKNOWLEDGMENTS}

This work was partly sponsored by "Vicerrectorado de Investigación, Desarrollo e Innovación" of the "Universitat Politècnica de Valencia" in the frame of the project "Estudio numérico de la cavitación en toberas de inyección Diesel mediante Grid Computing (Cavigrid)", Reference $\mathrm{N}^{\circ} 2597$ and by "Ministerio de Ciencia $e$ 
Innovación" in the frame of the project "Estudio teórico-experimental sobre la influencia del tipo de combustible en los procesos de atomización y evaporación del chorro Diesel (PROFUEL), reference TRA2011-26293. This support is gratefully acknowledged by the authors.

The authors would like to thank Mr. Cristian Ferrís and Mr. Joaquín de la Morena for their collaboration in the part of the computational tasks and mesh generation respectively. The authors would also like to thank the computer resources, technical expertise and assistance provided by the Universidad de Valencia in the use of the supercomputer "Tirant".

\section{REFERENCES}

[1] R. Payri, S. Molina, F.J. Salvador and J. Gimeno, A study of the relation between nozzle geometry, internal flow and spray characteristics in diesel fuel injection systems, KSME International Journal, 2004, vol. 18, issue 7, pp. 12221235.

[2] S.H. Park, H.K. Suh and C.S. Lee, Effect of bioethanol-biodiesel blending ratio on fuel spray behavior and atomization characteristics, Energy \& Fuels 2009, 23, pp. 4092-4098.

[3] R. Payri, J.M. García, F.J. Salvador, and J. Gimeno, Using spray momentum flux measurements to understand the influence of diesel nozzle geometry on spray characteristics, Fuel 2005, vol. 84, pp. 551-561.

[4] H.K. Suh and C.S. Lee, Effect of cavitation in nozzle orifice on the diesel fuel atomization characteristics, International journal of heat and fluid flow, 2008, 29, pp. 1001-1009. 
[5] V. Bermúdez, R. Payri, F.J. Salvador and J. Gimeno, Study of the influence of nozzle seat type on injection rate and spray behavior, Proceedings of the institution of mechanical engineers, Part-D, Journal of automobile engineering, 2005, vol. 219, issue D5, pp. 677-689.

[6] D.P. Schmidt and M.L. Corradini, The internal Flow of Diesel Fuel Injector Nozzles: a Review, International Journal of Engine Research 2001, vol. 2, nº1.

[7] C. Mishra and Y. Peles, Size scale effects on cavitating flows through microorifices entrenched in rectangular microchannels, Journal of microelectromechanical systems 2005, vol. 14, nº 5, pp. 987-999.

[8] R. Payri, F.J. Salvador, J. Gimeno and L.D. Zapata, Diesel nozzle geometry influence on spray liquid-phase fuel penetration in evaporative conditions, Fuel 2008, vol. 87, pp. 1165-1176.

[9] C. Soteriou, R. Andrews, M. Smith, Further studies of cavitation and atomization in Diesel injection, SAE Paper 1999-01-1486, 1999.

[10] W.H. Nurick, Orifice cavitation and its effect on Spray Mixing, Journal of Fluids Engineering 1976, vol. 98.

[11] F. Payri, V. Bermúdez, R. Payri, F.J. Salvador, The influence of cavitation on the internal flow and the spray characteristics in diesel injection nozzles, Fuel 2004, vol. 83, pp. 419-431.

[12] R. Payri, F.J. Salvador, J. Gimeno and J. de la Morena, Study of cavitation phenomena based on a technique for visualizing bubbles in a liquid pressurized chamber, Internal Journal of Heat and Fluid Flow 2009, vol. 30, pp. 768-777.

[13] C.V.K. Sarre, S.C. Kong and R.D. Reitz, Modeling the effects of Injector Nozzle geometry on Diesel sprays, SAE Technical Paper 1999, 1999-01-0912. 
[14] C.Y. Wang and C.E. Brennen, One dimensional Bubbly Cavitating flows through a converging-diverging nozzle, Transactions of the ASME 1998, vol. 120.

[15] Y. Chen and S.D. Heister, Modelling Hydrodynamic Non-equilibrium in Cavitating Flows, Transactions of the ASME 1996, vol 118.

[16] D.P. Schmidt, C.J. Rutland and M.L. Corradini, A fully compressible Twodimensional Model of High Speed Cavitating Nozzles, Atomization and Sprays 1999, vol. 9 .

[17] L. Liu, J. Li and Z. Feng, A numerical method for attached cavitation, International Journal for Numerical Methods in Fluids, 2006, 52, pp. 639-658.

[18] A.K. Singhal, M.M. Athavale, H. Li and Y. Jiangs, Mathematical basis and the full cavitation model, J. Fluids Eng., vol. 124, pp. 617-624, 2002.

[19] W. Yuan and GH. Schenerr, Numerical Simulation of Two-Phase Flow in Injection Nozzles: Interaction of Cavitation and External Jet Formation, Journal of Fluids Engineering, vol. 125, pp. 963-969, November 2003.

[20] E. Giannadakis, M. Gavaises, H. Roth and C. Arcoumanis, Cavitating Modelling in Single-Hole Diesel Injector Based on Eulerian-Lagrangian Approach, THIESEL 2004, Conference on Thermo and Fluid Dynamic Processes in Diesel Engines, Valencia, Spain, September, 10-13, 2004.

[21] T.G. Liu , B.C. Khoo and W.F. Xie, Isentropic one-fluid modelling of unsteady cavitating flow, Journal of computational physics, vol 201, 1, 80-108, 2004.

[22] C. Habchi, N. Dumont, O. Simonin, Multidimensional simulation of cavitating flows in diesel injectors by a homogeneous mixture modeling approach, Atomization and sprays, vol. 18, pp. 129 - 162, 2008. 
[23] F. Peng Kärrholm, Numerical Modelling of Diesel Spray Injection, Turbulence Interaction and Combustion, PhD. Thesis, Chalmers University of Technology, 2008.

[24] OpenCFD $®$ is a registered trade mark, http://www.opencfd.co.uk/

[25] F. Peng Kärrholm, H. Weller and N. Nordin, Modelling injector flow including cavitation effects for Diesel Applications, Proceedings of FEDSM2007, 5th Joint ASME/JSME Fluids Engineering Conference, July 30August 2007, San Diego, California, USA.

[26] J.M. Desantes, R. Payri, J.M. García, F.J. Salvador, A contribution to the understanding of isothermal diesel spray dynamics, Fuel 2007, vol. 86, pp. 1093-1101.

[27] G.M. Faeth, Structure and atomization properties of dense turbulence sprays, 23rd Symposium of Combustion, Université d'Orléans, France, pp. 1345-1352, 1990.

[28] A. Sou, S. Hosokawa and A. Tomiyama, Effects of cavitation in a nozzle on liquid jet atomization, International Journal of Heat and Mass Transfer, vol. 50, pp. 3575-3582, 2007.

[29] J. W. Lindau, R. F. Kunz, D.A. Boger, D. R. Stinebring and H.J. Gibeling, High Reynolds number unsteady multiphase CFD modeling of cavitating flows, J. Fluids Eng., vol. 124, pp. 607-616, 2002.

[30] F. Ruiz and L. He, Turbulence inside a cavitating injector orifice: A different kind, Atomization and Sprays, vol. 9, pp. 419 - 429, 1999.

[31] V. Macián, R. Payri, X. Margot, F.J. Salvador, A CFD Analysis of the Influence of Diesel Nozzle Geometry on the inception of Cavitation, Atomization and Sprays 2003, 13:579-604. 
[32] U. Flaig, W. Polach and G. Zieglet, Common rail system (CR-System) for passenger car DI Diesel engines. Experiences with applications for series productions projects, SAE Paper 1999-01-0191, 1999.

[33] V. Macián, V. Bermúdez, R. Payri and J. Gimeno, New technique for the determination of the internal geometry of diesel nozzle with the use of the silicone methodology, Experimental techniques, vol. 27 (2), pp. 39-43, 2003.

[34] M. Marcic, Measuring method for Diesel Multihole Injection Nozzles, Sensors and actuators 107, pp. 152-158, 2003.

[35] R. Payri, F.J. Salvador, J. Gimeno and G. Bracho, A new methodology for correcting the signal cumulative phenomenon on injection rate measurements, Experimental techniques, vol. 32, nº $1,2008$.

[36] R. Payri, H. Climent, F.J. Salvador and A.G. Favennec, Diesel injection system modeling. Methodology and application for a first-generation common rail system, Proc. Inst. Mech. Engrs. vol.218, part D, 2004.

[37] W. Bergwerk, Flow pattern in Diesel nozzle spray holes, Proc. Inst. Mech. Engrs. vol.173, nº 25, 1959.

[38] R.T. Knapp, W. D. James and G.H Frederic, "Cavitation”, McGraw-Hill, 1970.

[39] O. Coutier-Delgosha, J.L. Reboud and Y. Delannoy, Numerical simulation of the unsteady behavior of cavitating flows, Int. J. Numer. Meth. Fluids, vol. 42: pp. $527-548,2003$.

[40] E. Winkhofer, E. Kull, E. Kelz and A. Morozov, Comprehensive hydraulic and flow field documentation in model throttle experiments under cavitation conditions, ILASS-Europe 2001, Zurich, 2-6 September 2001. 
[41] C. Mishra and Y. Peles, Cavitation in flow through a micro-orifice inside a silicon microchannel, Physics of fluids vol. 17, $\mathrm{N}^{\mathrm{o}}$ 1, 013601, 2005.

\section{LIST OF TABLE AND FIGURE CAPTIONS}

Table 1: Nozzle's geometrical characteristics obtained by SEM visualization.

Table 2: Fluid properties considered throughout the work.

Table 3: Injection conditions used in the study.

Figure 1. Comparison of divergence terms (left: Gauss upwind, center: Van Leer, right: MUSCL).

Figure 2. Nozzle Geometrical characterization procedure.

Figure 3. Momentum test rig.

Figure 4. Cavitation in a nozzle.

Figure 5. Cavitation phenomena simplification.

Figure 6. 3D nozzle view and details of the grid.

Figure 7. Mesh sensitivity study done for multihole nozzles.

Figure 8. Vapour phase field as a function of time. Images are 1 microseconds apart. Pressure conditions $P_{i n j}=80 \mathrm{MPa}-P_{b a c k}=3 \mathrm{MPa}$.

Figure 9. Mass flow results (experimental and numerical) and vapour field average.

Figure 10. Mean values of pressure at the inlet section of the hole.

Figure 11. Comparison of time-averaged momentum flux and effective injection velocity as a function of $\sqrt{\Delta P}$ for all conditions at $P_{i n j}=30 \mathrm{MPa}$ and at $P_{i n j}=80 \mathrm{MPa}$.

Figure 12. Computational results against experimental data for the different flow coefficients. $P_{i n j}=30 \mathrm{MPa}-P_{b a c k}=3 \mathrm{MPa}$.

Figure 13. Computational results against experimental data for the different flow coefficients. $P_{i n j}=80 \mathrm{MPa}-P_{b a c k}=3 \mathrm{MPa}$. 
Figure 14. Density and velocity profiles in cavitating and non-cavitating conditions in a one-hole nozzle.

Figure 15. Comparison of vapour phase average laminar-RANS simulation for $\mathrm{P}_{\mathrm{inj}}=30$ $\mathrm{MPa}-\mathrm{P}_{\text {back }}=7 \mathrm{MPa}$.

\begin{tabular}{|c|c|c|c|c|c|c|}
\hline Nozzle & $D i[\mu \mathrm{m}]$ & $D o[\mu \mathrm{m}]$ & $\boldsymbol{k}$-factor $[-]$ & $\boldsymbol{r}[\boldsymbol{\mu m}]$ & $\boldsymbol{r} / \mathrm{Do}[-]$ & $L / D o[-]$ \\
\hline 6-hole & 170 & 170 & 0 & 13 & 0.074 & 5.71 \\
\hline
\end{tabular}

Table 1: Nozzle's geometrical characteristics obtained by SEM visualization.

\begin{tabular}{|c|c|c|}
\hline & Liquid & Vapour \\
\hline Density $\left(\mathrm{kg} / \mathrm{m}^{3}\right)$ & 830 & 0.1361 \\
\hline Viscosity $\left(\mathrm{kg} / \mathrm{ms}^{2}\right)$ & $3.6710^{-3}$ & $5.9510^{-6}$ \\
\hline Compressibility $\left(\mathrm{s}^{2} / \mathrm{m}^{2}\right)$ & $510^{-7}$ & $2.510^{-6}$ \\
\hline Saturation Pressure $(\mathrm{MPa})$ & \multicolumn{2}{|c|}{$5.410^{-3}$} \\
\hline
\end{tabular}

Table 2: Fluid properties considered throughout the work.

\begin{tabular}{|l|c|c|}
\hline & Injection Pressure (MPa) & Backpressure (MPa) \\
\hline Experimental & $30 \mathrm{MPa}$ & $9-7-5-3$ \\
\hline Modelling & $30 \mathrm{MPa}$ & $9-7-5-3-1-0.1$ \\
\hline Experimental & $80 \mathrm{MPa}$ & $9-7-5-3$ \\
\hline Modelling & $80 \mathrm{MPa}$ & $9-7-5-3$ \\
\hline
\end{tabular}

Table 3: Injection conditions used in the study. 

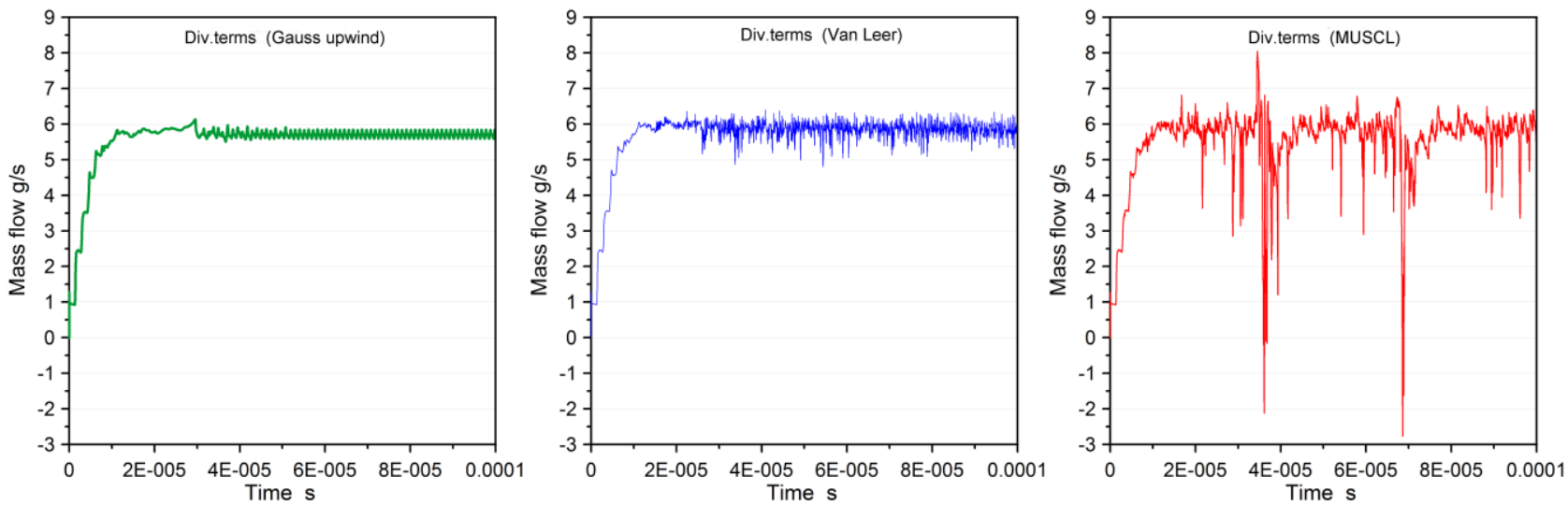

Figure 1. Comparison of divergence terms (left: Gauss upwind, center: Van Leer, right: MUSCL). 


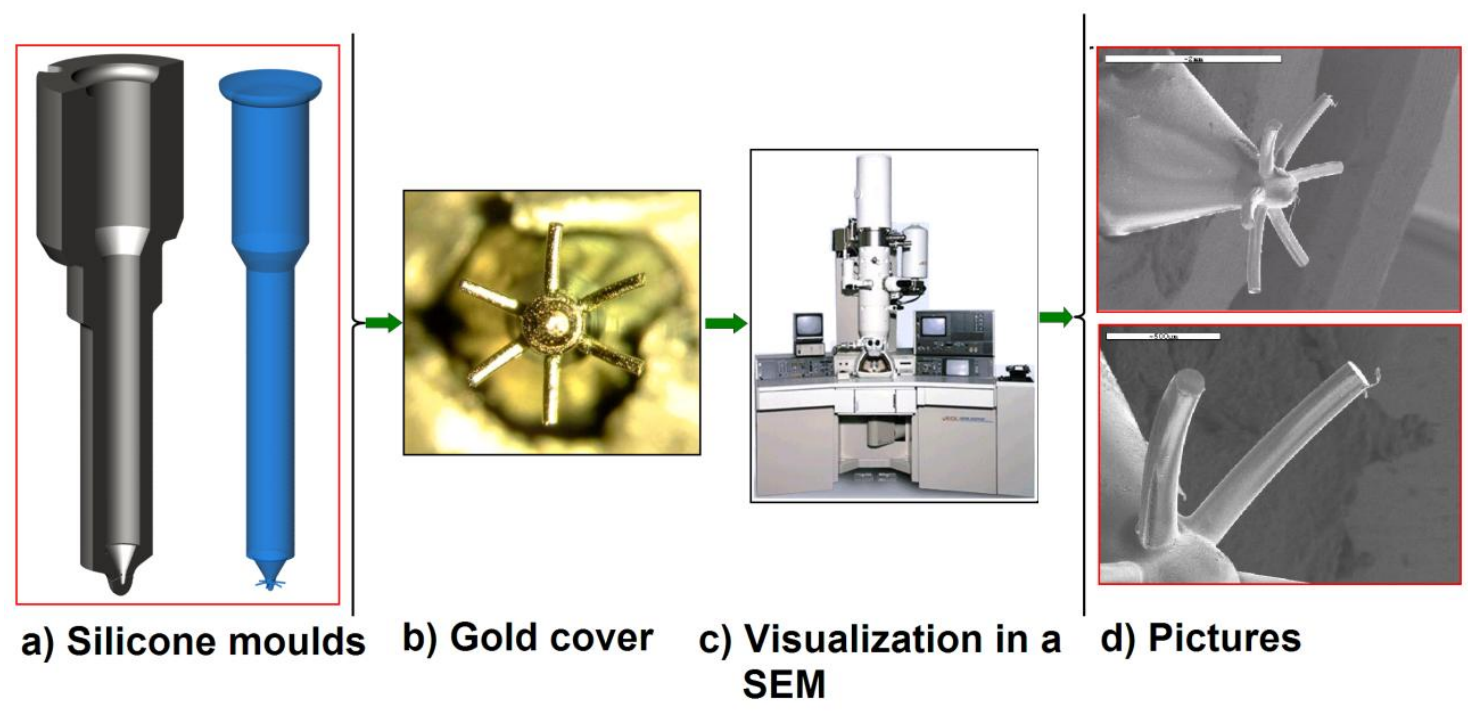

Figure 2. Nozzle Geometrical characterization procedure. 


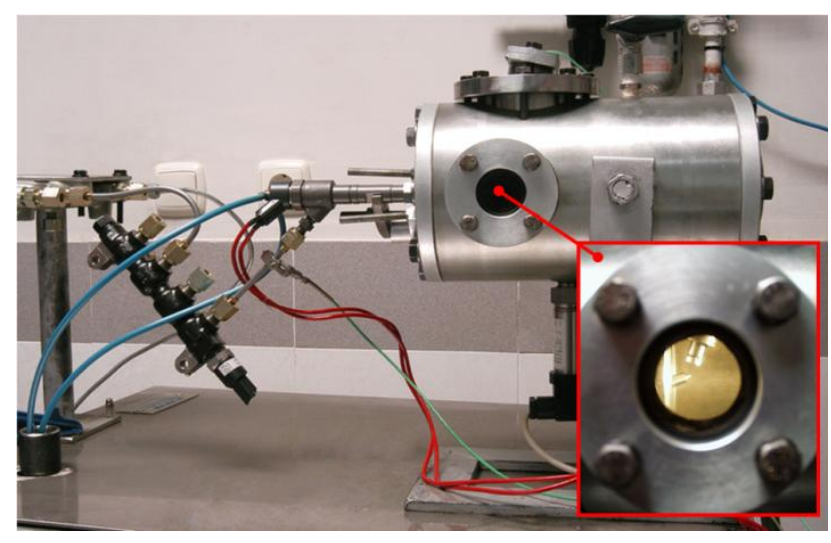

Figure 3. Momentum test rig. 


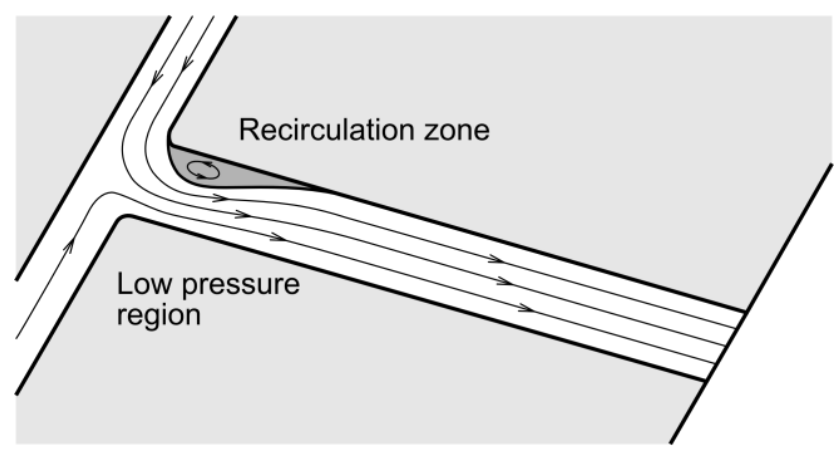

Figure 4. Cavitation in a nozzle. 


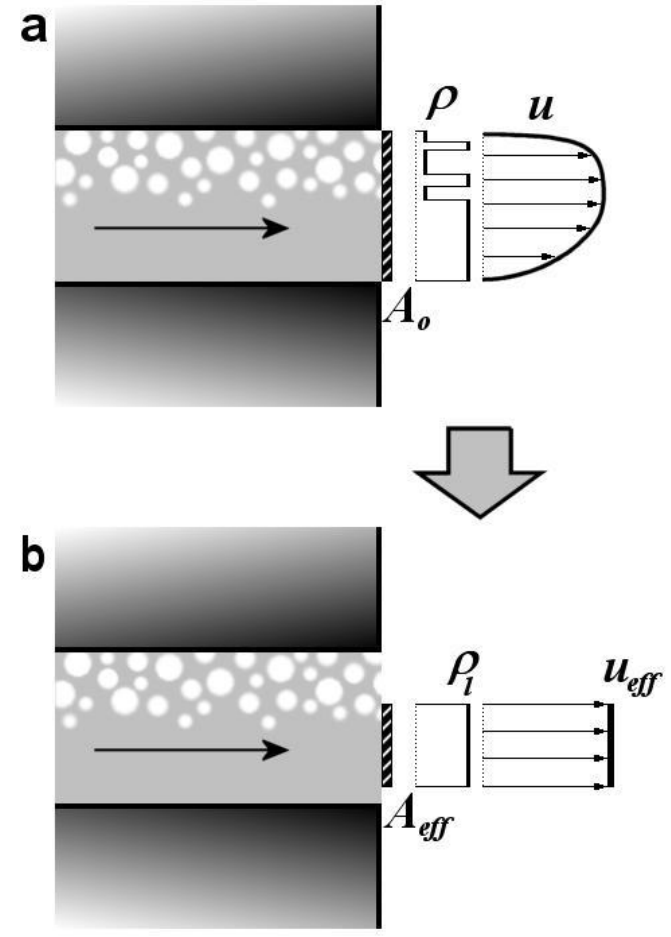

Figure 5. Cavitation phenomena simplification. 

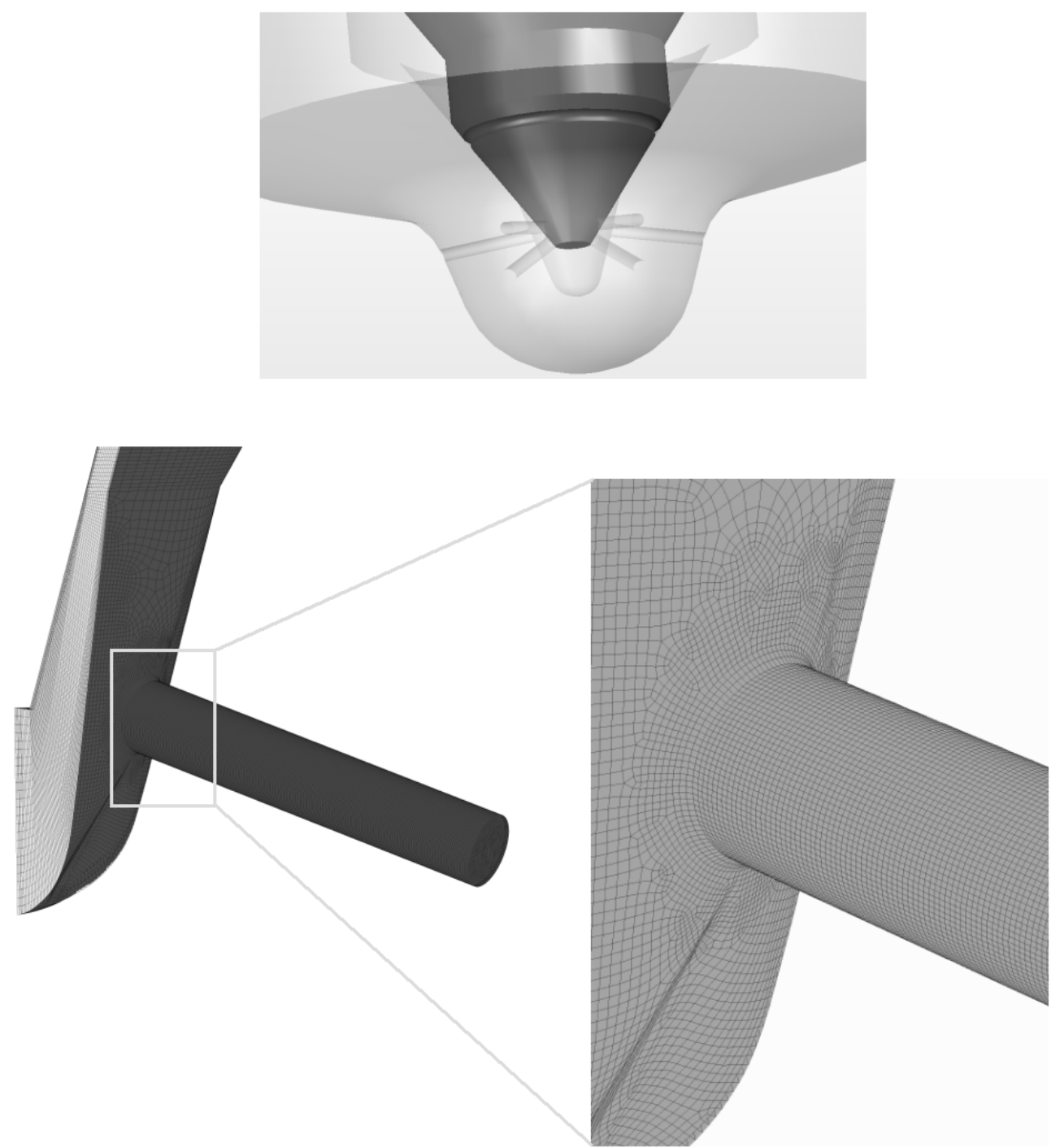

Figure 6. 3D nozzle view and details of the grid. 


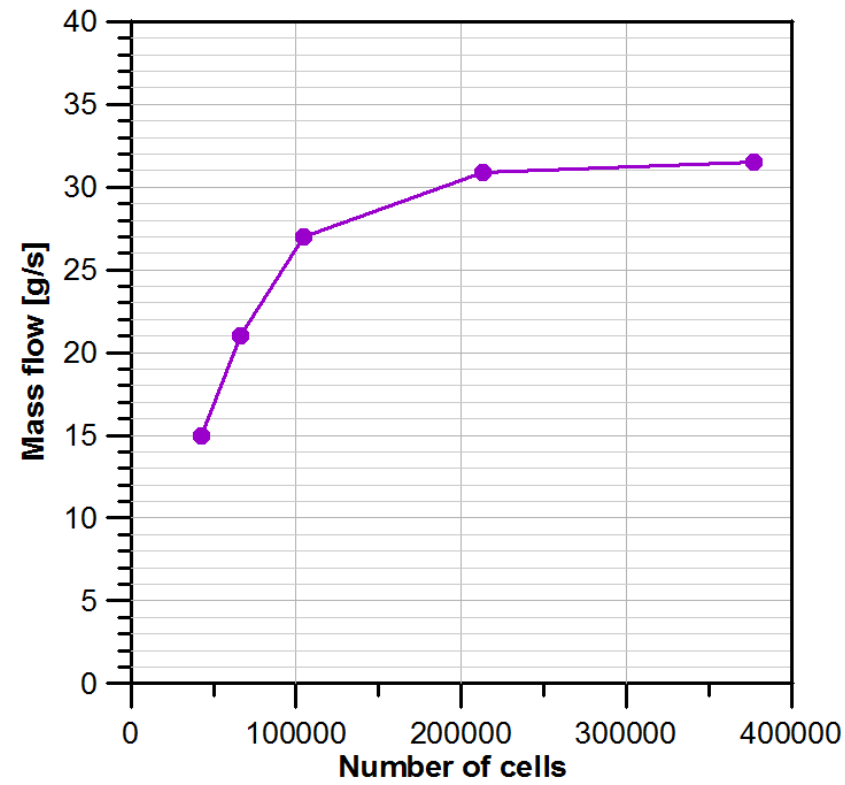

Figure 7. Mesh sensitivity study done for multihole nozzles. 


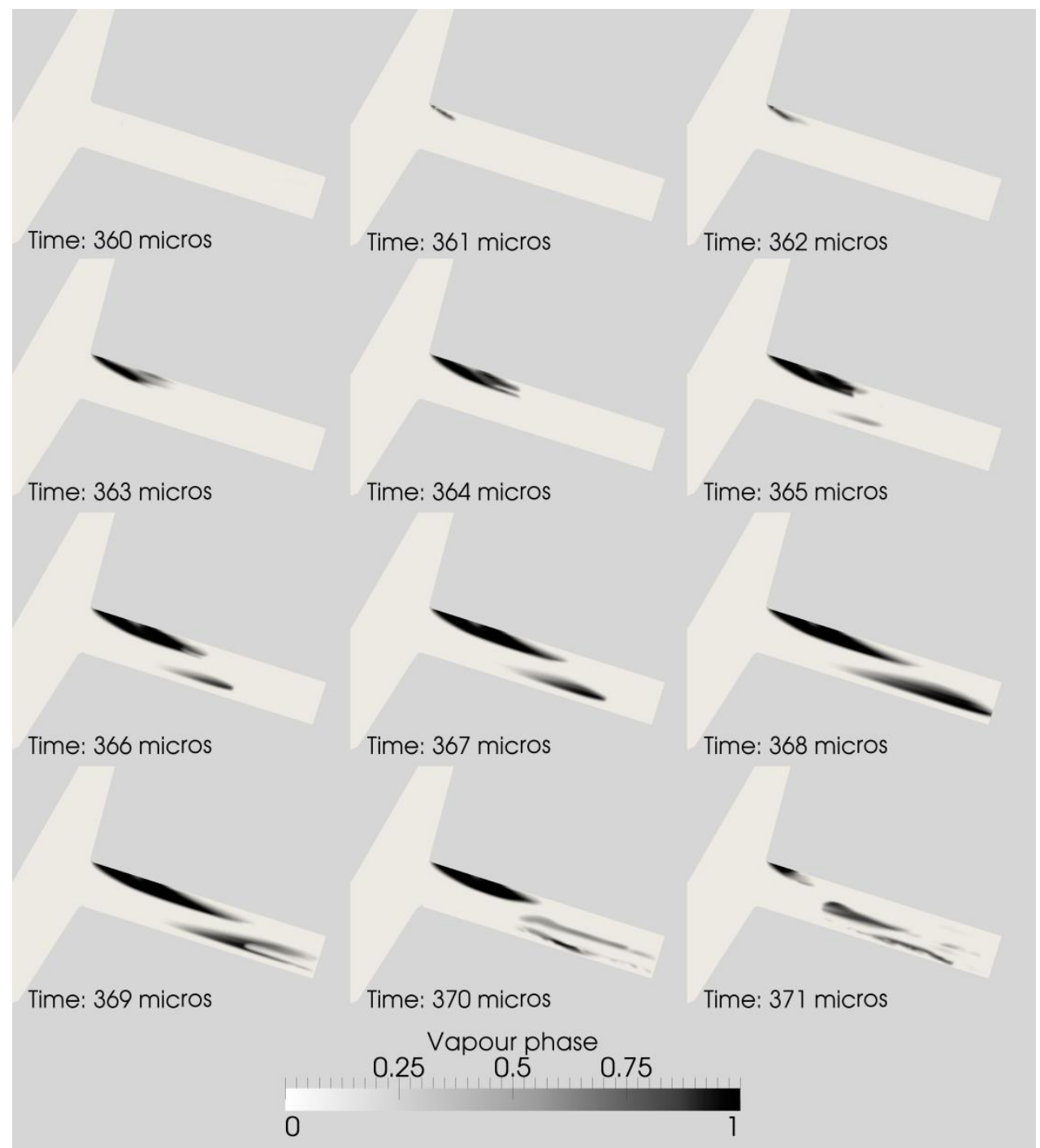

Figure 8. Vapour phase field as a function of time. Images are 1 microseconds apart. Pressure conditions $P_{i n j}=80 \mathrm{MPa}-P_{\text {back }}=3 \mathrm{MPa}$. 

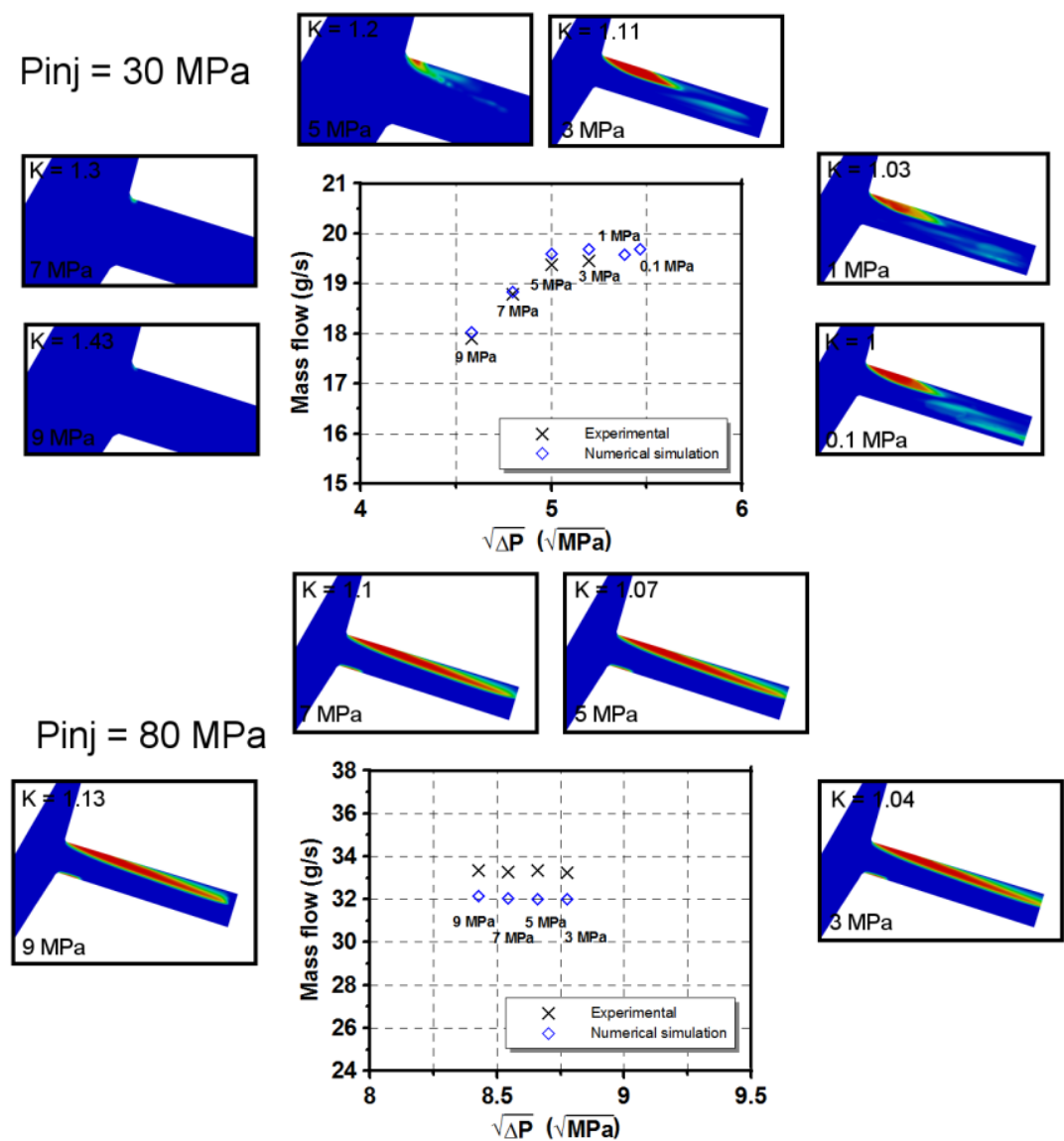

Figure 9. Mass flow results (experimental and numerical) and vapour field average. 

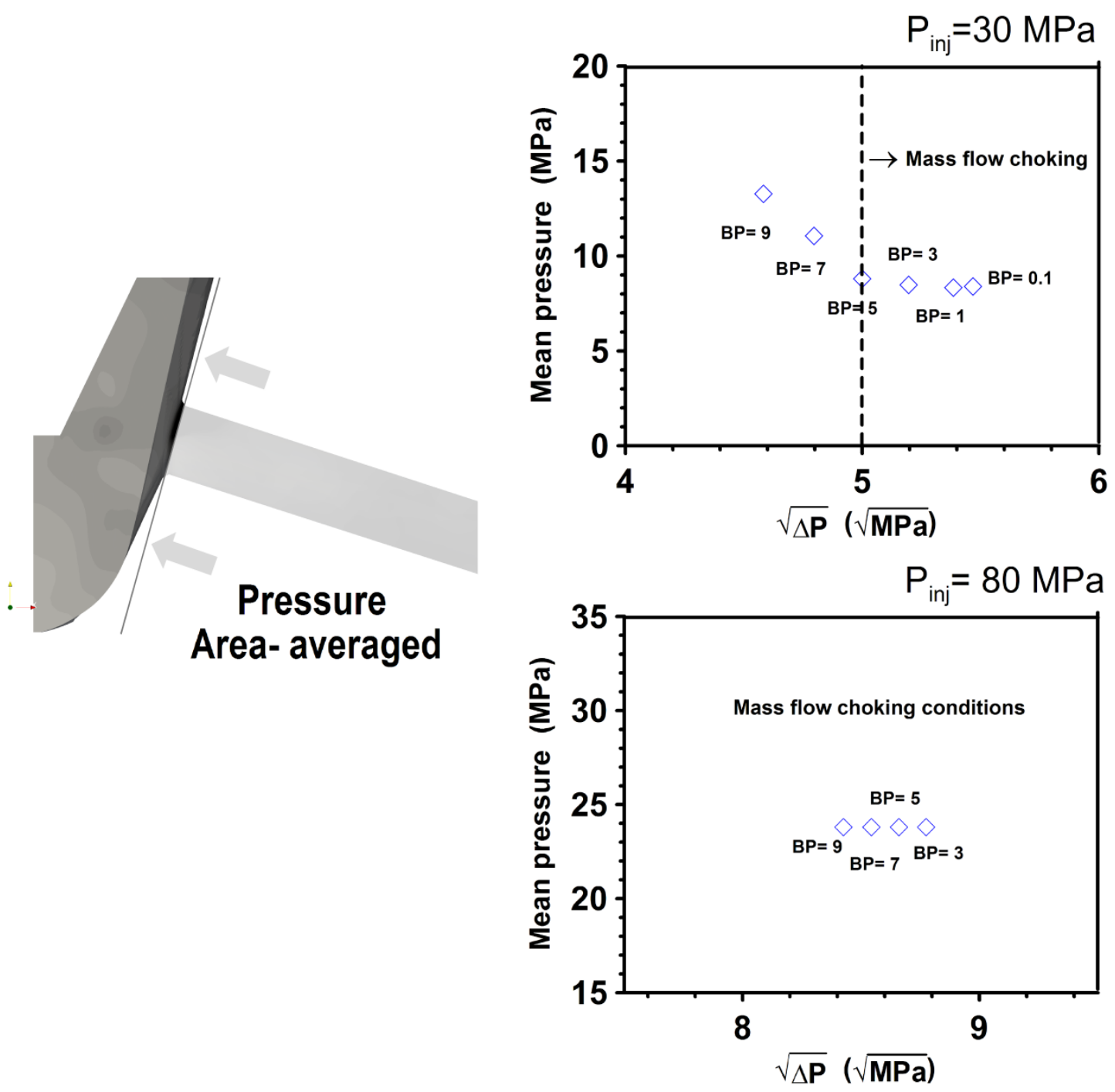

Figure 10. Mean values of pressure at the inlet section of the hole. 
$30 \mathrm{MPa}$
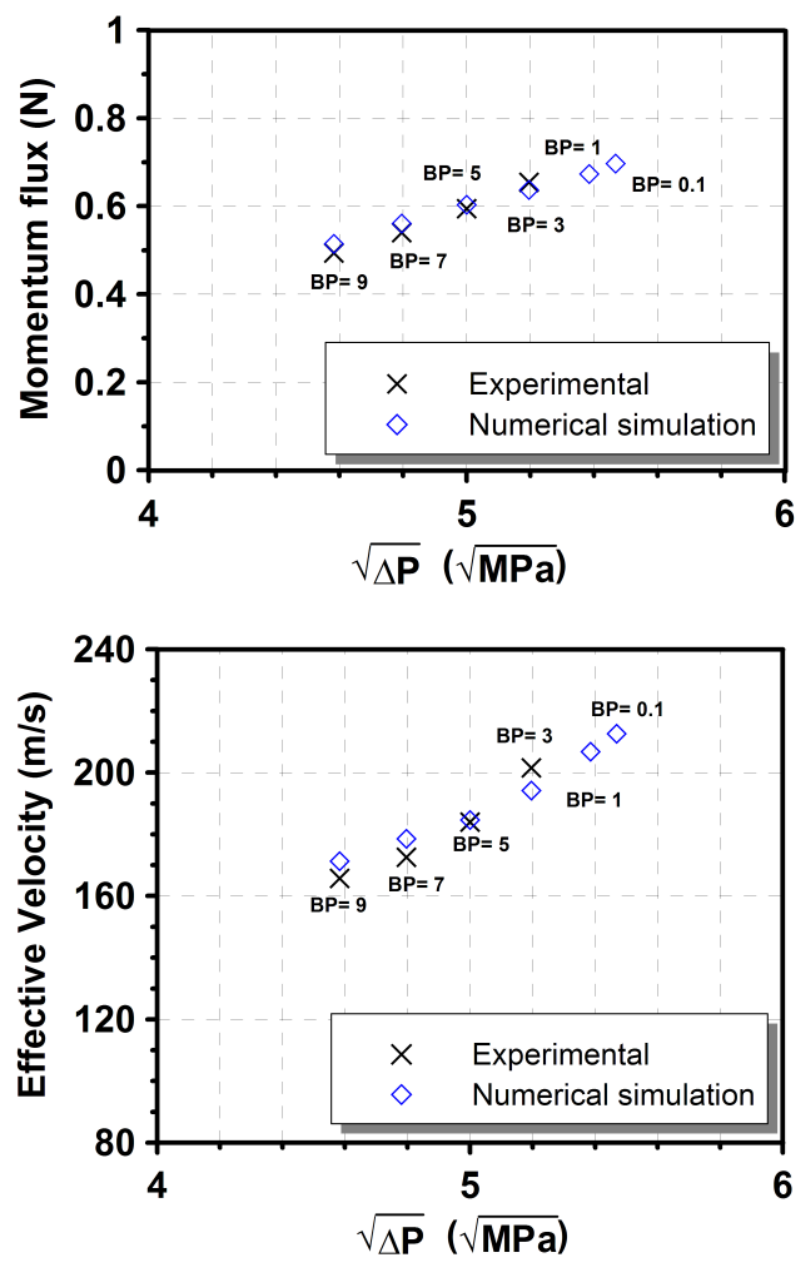

$80 \mathrm{MPa}$
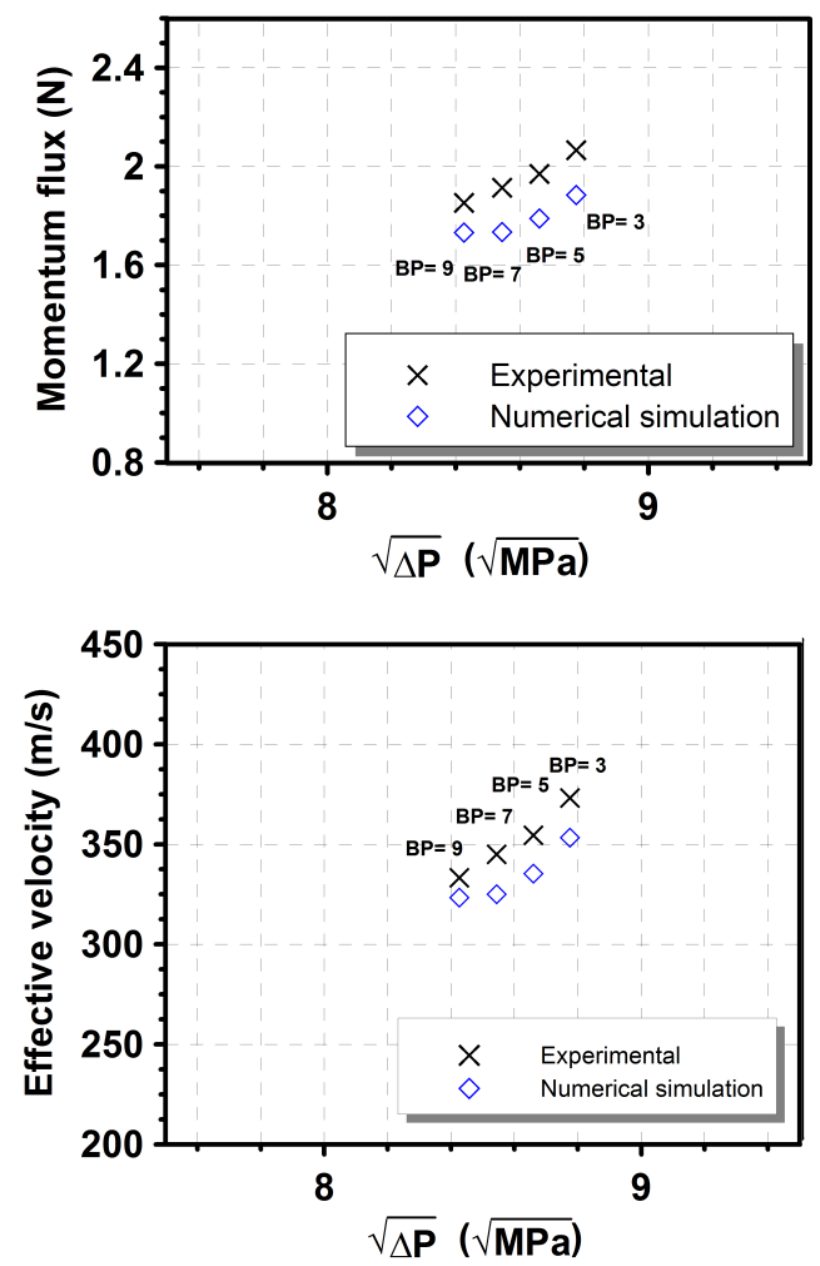

Figure 11. Comparison of time-averaged momentum flux and effective injection velocity as a function of $\sqrt{\Delta P}$ for all conditions at $P_{i n j}=30 \mathrm{MPa}$ and at $P_{i n j}=80 \mathrm{MPa}$. 


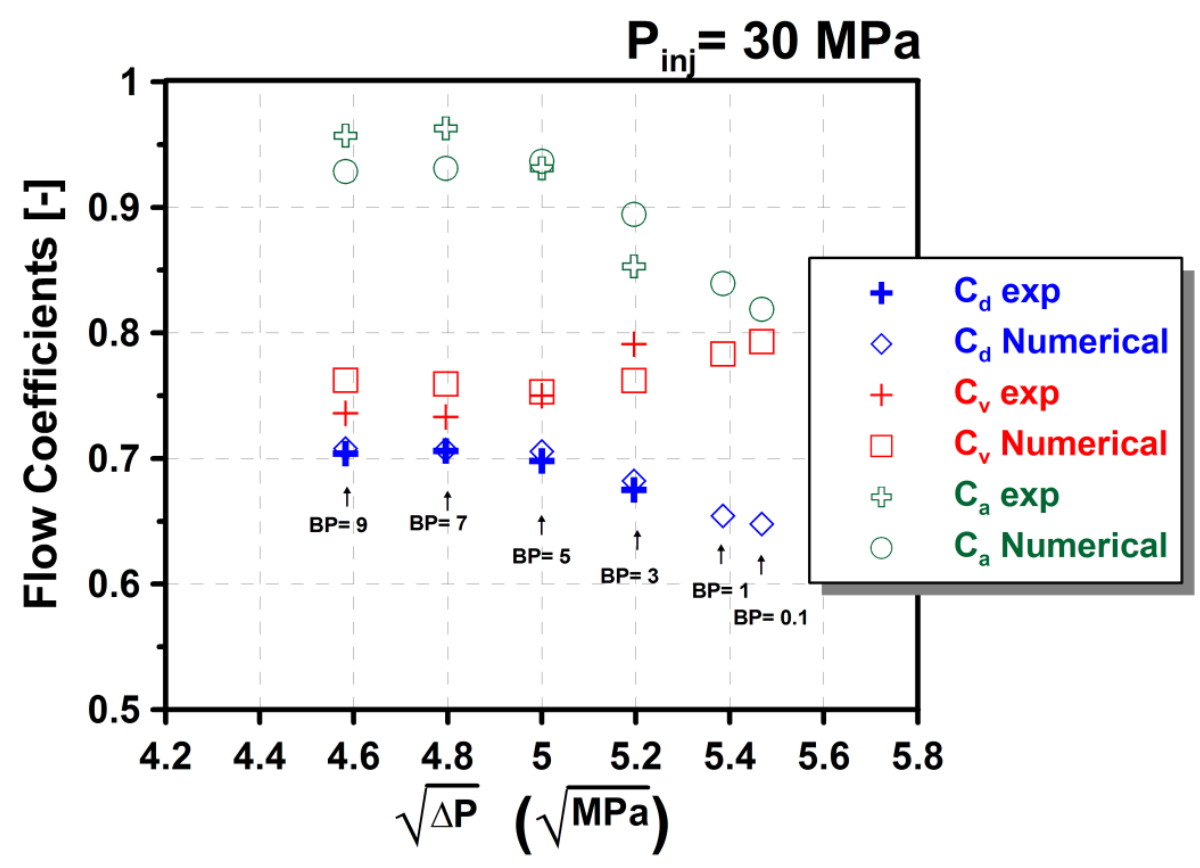

Figure 12. Computational results against experimental data for the different flow coefficients. $P_{i n j}=30 \mathrm{MPa}-P_{b a c k}=3 \mathrm{MPa}$. 


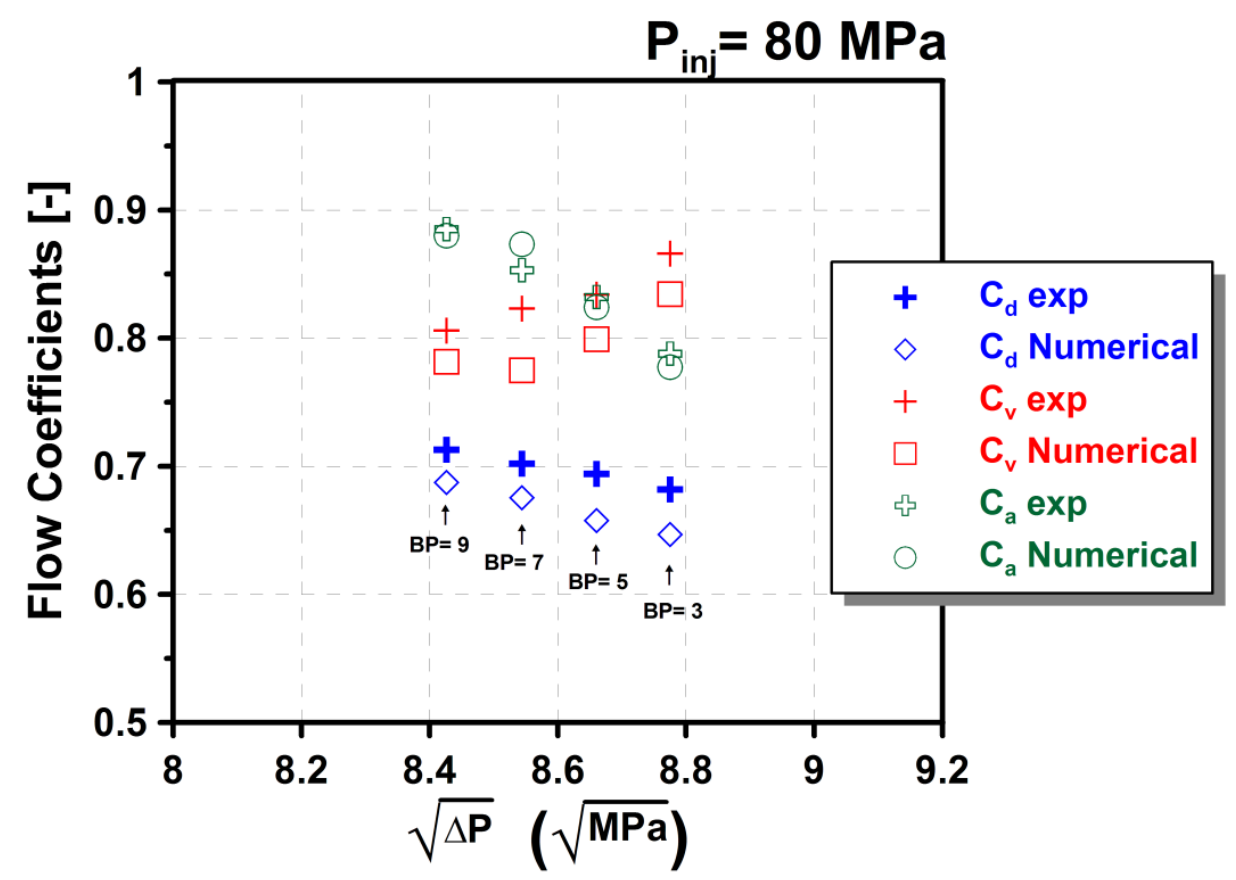

Figure 13. Computational results against experimental data for the different flow coefficients. $P_{i n j}=80 \mathrm{MPa}-P_{b a c k}=3 \mathrm{MPa}$. 


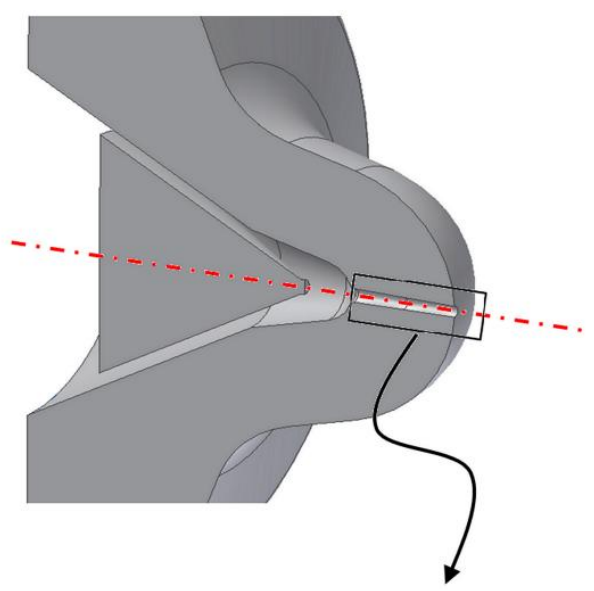

27.1 MPa - 0.1 MPa

$39 \mathrm{MPa}-12 \mathrm{MPa}$

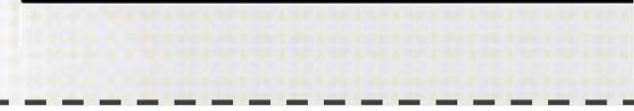

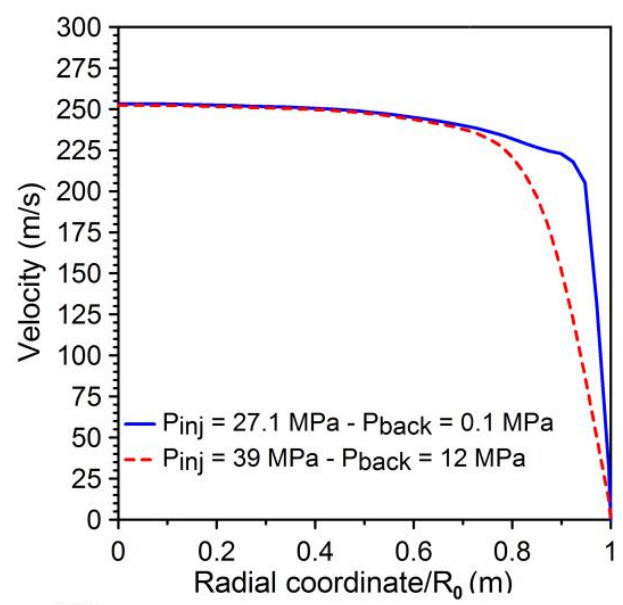

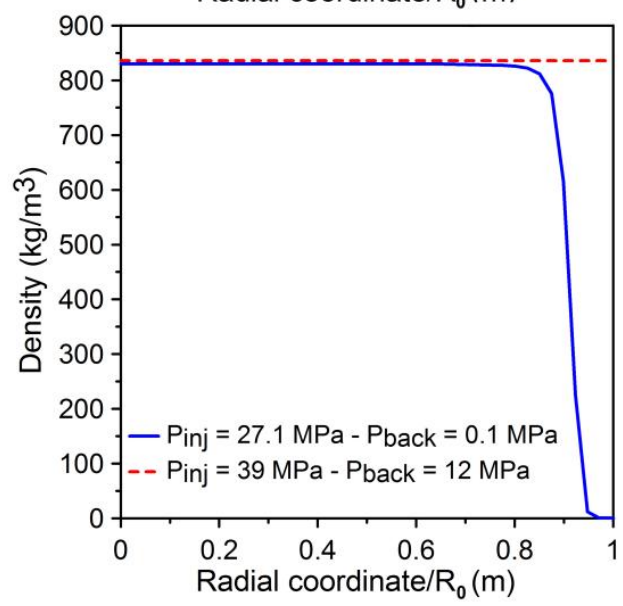

Figure 14. Density and velocity profiles in cavitating and non-cavitating conditions in a one-hole nozzle. 


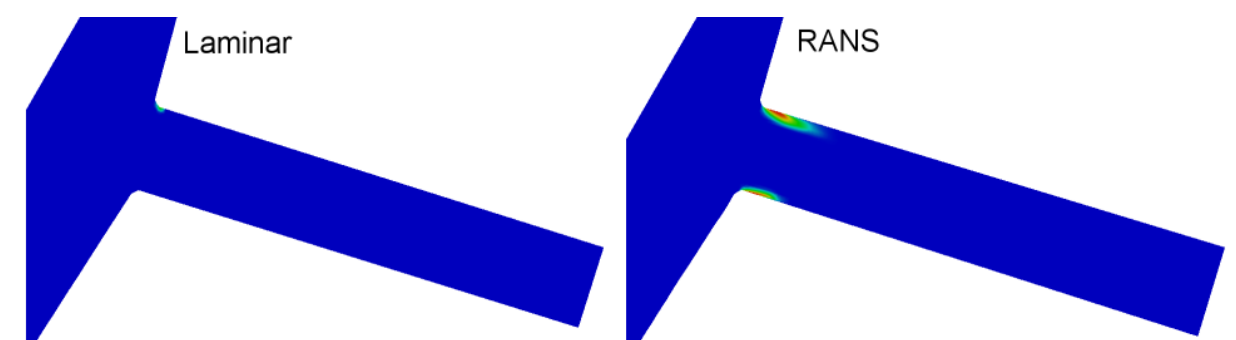

Figure 15. Comparison of vapour phase average laminar-RANS simulation for $\mathrm{P}_{\mathrm{inj}}=30$ $\mathrm{MPa}-\mathrm{P}_{\text {back }}=7 \mathrm{MPa}$. 